\title{
ESTUDO SOBRE FRENTES QUENTES QUE OCORREM NO SUL DO BRASIL
}

\author{
MARIA HELENA DE CARVALHO ${ }^{1}$, NATALIA FEDOROVA ${ }^{2}$ \\ ${ }^{1}$ Departamento de Meteorologia, Universidade Federal de Pelotas, Pelotas, RS, Brasil \\ ${ }^{2}$ Instituto de Ciências Atmosféricas, Universidade Federal de Alagoas (UFAL), Maceió, AL, Brasil \\ mhcar@uol.com.br, natalia@dimin.net
}

Recebido Março 2010 - Aceito Dezembro 2010

\begin{abstract}
RESUMO
Este trabalho apresenta o comportamento de duas frentes quentes que afetaram o tempo no estado do Rio Grande do Sul. Imagens de satélite e vários campos meteorológicos foram analisados para ambas as situações. Na primeira situação o sistema deslocou-se da Argentina e foi atingindo gradualmente as diversas regiões do estado, de oeste para leste. Durante a passagem deste sistema foi registrada a ocorrência de precipitação; em algumas estações do litoral, foram observadas nuvens cumulonimbus. Durante aproximadamente 24 horas o estado do Rio Grande do Sul esteve sob a influência do sistema. No segundo caso, uma frente quente atingiu o referido estado, enquanto o vórtice ao qual ela estava associada, ainda encontrava-se no Oceano Pacífico. Para este segundo caso, foram construídas seções verticais de temperatura potencial e observou-se uma inclinação das superfícies isentrópicas, a qual está relacionada com movimento ascendente. A análise de mesoescala mostrou que existia uma região com pressões mais altas no nordeste do estado e pressões baixas no oeste/noroeste. Neste segundo caso, também foram observadas nuvens cumulonimbus em várias estações do estado, incluindo algumas na parte oeste do estado. Foi registrada também a ocorrência de nevoeiros nas duas situações. Palavras-chave: frente quente, sistemas frontais, previsão do tempo
\end{abstract}

\begin{abstract}
STUDY ABOUT WARM FRONTS THAT OCCUR IN SOUTHERN BRAZIL
This paper presents the behavior of two warm fronts which affected the weather in Rio Grande do Sul state. Satellite images and various meteorological fields were analyzed for both situations. In the first one the system moved from Argentina and gradually reached the various regions of the state, from the west to the east. During the passage of this system, occurrence of precipitation was registered; in some stations of the shore, cumulonimbus clouds were observed. During about 24 hours the Rio Grande do Sul state was under the influence of that system. In the second case, the warm front that reached the same state was not associated with a clearly defined vortex. In the second situation, a warm front arrived at state mentioned earlier, while the vortex to which the front was associated, was still over the Pacific Ocean. For this case, vertical sections of potential temperature were constructed and it was observed a slope of the isentropic surfaces, which is related to the presence of vertical motions. The mesoscale analysis showed that there was a region with higher pressures in the northeast region of Rio Grande do Sul and lower pressures in the west/northwest. Also in this second situation cumulonimbus clouds were observed in various stations of the state, including some in the west part of the state. It was also registered the occurrence of fog during the two situations.
\end{abstract}

Keywords: warm fronts, frontal systems, weather forecasting 


\section{INTRODUÇÃO}

Os sistemas frontais que atingem a Região Sul do Brasil têm uma influência importante na precipitação e temperatura observadas nesta região. Assim, o conhecimento da estrutura destes sistemas, bem como, das condições meteorológicas associadas a eles é fundamental para a elaboração das previsões de tempo.

O primeiro modelo frontal para o ciclone extratropical e suas frentes associadas foi elaborado por Bjerknes e Solberg (1922), os quais pertenciam à chamada escola norueguesa. Para chegar a este modelo, eles contavam basicamente com dados de superfície. Após o surgimento dos dados de altitude, foram publicados trabalhos científicos que explicavam a estrutura, dinâmica e os fenômenos associados às frentes em geral incorporando estas novas informações. Por exemplo, pode-se citar Browning (1986), que apresentou modelos conceituais de frentes térmicas, baseados nos conceitos de esteiras transportadoras.

As frentes frias têm recebido alguma atenção dos pesquisadores no Brasil. Por exemplo, Kousky (1979) estudou o movimento de uma frente fria ao longo da costa leste do Brasil, acompanhado de um deslocamento do máximo de atividade pluviométrica do leste da Amazônia para o leste do Brasil. Oliveira (1986) analisou as interações entre os sistemas frontais na América do Sul e a convecção na Amazônia.

Por outro lado, as frentes quentes não têm sido objeto de estudo, provavelmente devido à baixa freqüência com que estes sistemas aparecem no Brasil, e também porque eles só são observados na região sul do país (Lima, 1985). A frente quente é freqüentemente fraca e limitada em extensão horizontal, especialmente para sistemas ciclônicos maduros e em fase de dissipação (Mass, 1991). Além disso, nota-se que para muitas depressões a frente quente é difícil de ser localizada (Hoskins e Heckley, 1981) e nem todos os ciclones extratropicais estão associados com frentes quentes bem definidas (Bluestein, 1993).

Um dos poucos trabalhos que fazem referência às frentes quentes observadas no Brasil é o de Lima (1985). Segundo ele, estas frentes ocorrem nos meses de outono, inverno e primavera. Desse modo, verifica-se que o Brasil está carecendo de estudos acerca das frentes quentes e das condições meteorológicas a elas associadas. O entendimento do comportamento destes sistemas irá auxiliar os previsores de tempo na elaboração de seus prognósticos, nas situações em que se verifique a presença de uma frente quente.

As frentes quentes podem estar associadas à ocorrência de chuvas fortes. Exemplos desta situação foram encontrados por Severo (1994). No período estudado (1978 a 1984), ele observou três casos de sistemas frontais que passaram pela
Região Sul do Brasil e depois retrocederam como frente quente. Dois casos foram verificados no outono e um no inverno.

O problema da localização das frentes quentes no Hemisfério Sul foi enfocado por Taljaard (1972). Ele mostrou os vários estilos de análise frontal no Hemisfério Sul. Segundo Taljaard, mapas publicados entre 1945 e 1965 revelam muitas peculiaridades de estilo e interpretações muito diferentes dos mesmos dados. De acordo com ele, alguns analistas omitiam as frentes quentes de todos os ciclones, exatamente pela dificuldade em detectá-las.

Por serem sistemas que têm influência nas condições do tempo em várias partes do Hemisfério Norte, diversos estudos têm sido elaborados a respeito das frentes quentes naquele hemisfério.

Entre as características associadas às frentes quentes, tem-se que as zonas frontais quentes, geralmente inclinam-se menos na vertical do que as zonas frontais frias (Bluestein, 1993). O movimento em direção ao pólo ou na direção nordeste de uma frente quente no Hemisfério Norte está usualmente associado com uma forte advecção quente em baixos níveis a leste, ou em direção ao pólo, e na parte leste de um ciclone à superfície em desenvolvimento ou que esteja se intensificando. Em relação ao giro do vento, ele ocorre no sentido horário no Hemisfério Norte na passagem de uma frente quente (Bluestein, 1993). Na vertical, ocorre um giro do vento no sentido antihorário no Hemisfério Sul (Lima, 1985). Outra característica observada nas frentes quentes é uma inclinação frontal de aproximadamente 1:100 (Neiman et al, 1998).

Algumas deficiências do modelo frontal desenvolvido na Noruega, no final da segunda década do século vinte, foram apontadas por Mass (1991), num artigo em que foi feita uma revisão de modelos conceituais de frentes. Uma aparente deficiência do modelo clássico é que um dos seus componentes mais importantes, a frente quente, é freqüentemente fraca e limitada em sua extensão horizontal, especialmente para sistemas maduros e em dissipação. Ele também fez referência a Anderson et al. (1973), segundo os quais nem sempre é possível identificar frentes quentes em imagens de satélite.

As diferenças entre as estruturas de frentes frias e quentes em ondas baroclínicas usando modelos de frontogênese foram mostradas por Hoskins e Heckley (1981). Eles observaram, por exemplo, que na frente fria existe uma coincidência de vorticidade positiva (Hemisfério Norte) e gradientes de temperatura significativos em toda a profundidade. Por outro lado, esta característica importante não foi observada nas frentes quentes por eles estudadas. Eles consideraram dois tipos de frentes quentes: uma fraca (tipo A) e outra mais intensa (tipo B). Em ambos tipos de frentes quentes, o gradiente de temperatura estava associado a vorticidade positiva significativa somente nos níveis baixos. Eles encontraram também que a frente quente 
tipo A é muito similar à frente fria, embora bem mais fraca. A frente quente tipo B é muito diferente: existe convergência de baixos níveis somente adiante do ar frio. A região frontal é dominada por ascensão. Eles encontraram, também, que as inclinações da frente fria e das frentes quentes tipos A e B são de, aproximadamente, 1/80, 1/90 e 1/130, respectivamente.

Tem sido observado que chuva relativamente uniforme devida somente a ascendência dinâmica de grande escala, está freqüentemente presente adiante de frentes quentes ativas (Browning e Harrold, 1969). Contudo, ocasionalmente, como no estudo que eles realizaram, a chuva muda o seu caráter e continua no setor quente. Em algumas frentes quentes, a precipitação não é uniformemente distribuída; ao invés disso, ela ocorre com características de mesoescala irregulares e na forma de banda (Locatelli e Hobbs, 1987). No caso de uma frente fria em altitude alcançar a frente quente em superfície, o cinturão de precipitação estará orientado paralelo à frente fria em altitude, em vez de paralelo à frente quente em superfície (Browning, 1986).

Num estudo de caso de frente quente analisando as áreas de precipitação de meso-escala dentro deste sistema, Atkinson e Smithson (1978) encontraram três tipos de áreas grandes de precipitação de meso-escala: uma linear e paralela à frente, uma linear e perpendicular à frente e uma não linear e que se movia através da frente. Em todos os casos, a causa principal da área de precipitação parecia ser a liberação de instabilidade potencial pela ascensão de escala sinótica. No Rio Grande do Sul, sistemas de mesoescala que provocam precipitação podem ser encontrados associados à presença de frentes quentes (Abdoulaev et al., 1996).

Campos de nuvem relacionados com frentes quentes, obtidos através de imagens de satélite foram analisados por Fedorova e Bakst (1996). Eles apresentaram a análise visual dos campos de nebulosidade, usando imagens de satélite dos Hemisférios Norte e Sul, para identificar seções frontais dos vários tipos de frentes, entre elas, as frentes quentes.

A presença de uma frente quente localizada entre o Rio Grande do Sul e o Uruguai pode estar associada a uma futura ciclogênese próximo a esta região (Diniz, 1984). O mesmo tipo de situação também foi relatado por Lima (1985) para situações de frentes estacionárias na região sul do Brasil. Segundo ele, uma frente estacionária pode deslocar-se como frente quente até uma região frontogenética dinâmica e depois voltar a se deslocar para latitudes mais baixas, como frente fria.

O objetivo deste trabalho é mostrar as características de frentes quentes e setores quentes de ciclones extratropicais, que são observados na região sul do Brasil. Foram selecionados dois casos para estudo: um típico e outro cuja identificação torna-se mais complicada, conforme explicações na seção 2.

\section{DADOS E METODOLOGIA}

Foram escolhidos dois casos de ocorrência de frentes quentes que afetaram as condições de tempo no Rio Grande do Sul: 30 de junho de 1998 (primeiro caso) e $1^{\circ}$ de outubro de 1999 (segundo caso). O primeiro caso foi escolhido por ser típico, ou seja, a frente quente apresentava uma banda frontal característica na imagem de satélite e estava associada a um vórtice ciclônico. $\mathrm{O}$ segundo caso foi selecionado porque apresentou a nebulosidade associada à frente quente muito larga, mas o centro da espiral do vórtice não estava bem definido. No campo de pressão na região do sistema, estava localizado um cavado fraco, conforme será mostrado na seção 3.2.2. Uma massa de nebulosidade parecida já foi descrita antes (Fedorova e Bakst, 1999), mas não foi estudada sua estrutura e ligação com frentes quentes.

Para analisar-se a situação sinótica associada ao primeiro caso, usaram-se campos das análises (0000 UTC) do National Centers for Environmental Prediction (NCEP), Estados Unidos, existentes no arquivo do Centro de Pesquisas e Previsões Meteorológicas (CPPMet), da Faculdade de Meteorologia/ Universidade Federal de Pelotas. O campo de água precipitável para o dia 30 de junho de 1998 - 0000 UTC (dados do NCEP) foi obtido diretamente do site do Climate Diagnostics Center/ NOAA, pois não estava disponível no arquivo do CPPMet. A resolução do modelo do NCEP é $1^{\circ}$ x. $1^{\circ}$ de latitude/longitude.

Para o segundo caso, foram usadas as previsões para 12 horas do mesmo centro, uma vez que às 0000 UTC o sistema começava a entrar no Rio Grande do Sul. No arquivo do CPPMet não existem análises do NCEP para 12 horas, somente previsões. Também foram analisadas imagens do satélite GOES-8, nos canais infravermelho (IV) e do vapor d'água (WV), dos dois casos, obtidas no arquivo do CPPMet. Foram usadas imagens de vários horários, de acordo com o período do dia em que foram observadas as frentes. A identificação das frentes quentes nas imagens de satélite foi realizada segundo Anderson et al. (1973). Foram usados dados de várias estações meteorológicas do Rio Grande do Sul e de Santa Catarina, tirados de boletins sinóticos, fornecidos pelo Oitavo Distrito de Meteorologia (do INMET - Instituto Nacional de Meteorologia), em Porto Alegre - RS. Os dados estavam disponíveis para os horários de 0000, 1200 e 1800 UTC. Nestes boletins são informados: pressão atmosférica, direção e velocidade do vento, temperatura do bulbo seco, temperatura do ponto de orvalho, cobertura de nuvens, tendência da pressão, tempo presente, tempo passado e taxa de precipitação. Com estes dados foram construídas cartas sinóticas para o Rio Grande do Sul e Santa Catarina, nas quais foram traçadas isóbaras.

Os dados de radiossondagem da estação do Aeroporto Salgado Filho, em Porto Alegre, fornecidos pela Diretoria de Eletrônica e Proteção ao Vôo, para o primeiro caso, foram plotados num diagrama termodinâmico Skew $\mathrm{T}, \log \mathrm{p}$, a fim de 
se verificar a estabilidade da atmosfera e com eles também foram calculados três índices de estabilidade da atmosfera: Showalter, K e Total Totals (Bluestein, 1993). .

Para este mesmo caso, usaram-se também dados de temperatura e depressão do ponto de orvalho do modelo do NCEP, para vários níveis, para construir os perfis verticais de temperatura e de temperatura do ponto de orvalho de algumas localidades do Rio Grande do Sul, com o objetivo de avaliar a energia de instabilidade. O cálculo desta energia foi efetuado da mesma forma que em Fedorova e Khan (1999). Os cálculos foram realizados de acordo com o Manual de Previsão de Curto Prazo (1986). Para as mesmas localidades, também foram determinados, através de cálculos, os três índices de estabilidade atmosférica citados anteriormente, os quais, para Porto Alegre, foram calculados com dados de radiossondagem.

Para a situação de 30 de junho de 1998, foram calculadas as trajetórias das parcelas de ar (30 horas) para os níveis de 1000, 850,700 e $500 \mathrm{hPa}$ por um método gráfico no qual são utilizadas cartas de altura geopotencial (Fedorova, 1999). Também para este caso calculou-se a advecção térmica, a qual foi obtida com base nas trajetórias das parcelas. Estes métodos têm sido usados operacionalmente no Centro Hidrometeorológico da Rússia há muitos anos e estão descritos em Fedorova (1999). Neste trabalho os cálculos foram feitos na mesma maneira que em Pedrotti e Fedorova (2000). Para o segundo caso, não foi possível usar-se o mesmo método para determinação das trajetórias, em função dos ventos na região de interesse apresentarem intensidades muito pequenas.

Para o segundo caso, foram construídas seções transversais verticais paralelas e perpendiculares à frente, nas quais se analisou a temperatura potencial. Associando-se esses perfis com o campo do movimento horizontal, podem-se obter informações sobre o movimento vertical, de acordo com Vasquez (2000). Ele apresenta uma seção transversal vertical construída numa direção que atravessa uma frente quente nas planícies do norte dos Estados Unidos. De acordo com Vasquez, como as temperaturas em baixos níveis diminuem na direção dos pólos e o ar tende a se deslocar ao longo das superfícies isentrópicas sob condições adiabáticas, então, se o vento sopra numa direção que o faz subir ao longo de uma destas superfícies, produzem-se movimentos verticais. Conseqüentemente, podem formar-se nuvens e, possivelmente, precipitação. As temperaturas potenciais foram calculadas de acordo com Hess (1959).

\section{RESULTADOS}

\subsection{Situação do dia 30 de junho de 1998}

\subsubsection{Identificação das zonas frontais usando imagens de satélite}

Pela análise da imagem das 0000 UTC do dia 30 de junho de 1998 (Figura 1), verifica-se que existe um vórtice ciclônico sobre a Argentina, associado a uma frente fria que atinge o Oceano Pacífico e uma frente quente, cuja banda frontal se estende sobre o Uruguai e abrange uma grande parte do Rio Grande do Sul. Segundo Fedorova e Bakst (1996) e também de acordo com a identificação clássica de Anderson et al. (1973), as frentes quentes são identificadas pela sua posição relativa ao vórtice ciclônico. Sua banda de nebulosidade apresenta curvatura anticiclônica e aparecem muitos cirrus a leste desta curvatura.

Observando-se a imagem da Figura 1, nota-se que sobre o Rio Grande do Sul, a maior parte da nebulosidade associada à frente quente era do tipo estratiforme, existindo algumas nuvens cumulunimbus no litoral sul deste estado e também sobre o Uruguai.

A frente continuou influenciando o tempo no litoral do Rio Grande do Sul durante o dia 30 de junho, o que pode ser observado na Figura 2 que mostra a imagem de satélite no espectro do vapor d'água para as 1145 UTC do dia 30 de junho. Em algumas regiões do estado houve formação de nuvens convectivas. Conforme pode ser observado na Figura 3, às 1745 UTC a referida frente já havia deixado o Rio Grande do Sul. Neste horário estava atuando sobre este estado o setor quente do vórtice ciclônico.

\subsubsection{Análise dos campos de pressão, tendência de pressão e altura geopotencial}

Serão mostrados e discutidos aqui campos de parâmetros meteorológicos do NCEP para as 0000 UTC do dia 30 de junho de 1998.

O campo de pressão reduzida ao nível do mar para o dia e horário referidos acima (Figura 4) mostra que, neste nível, a frente estava localizada no bordo oeste do anticiclone

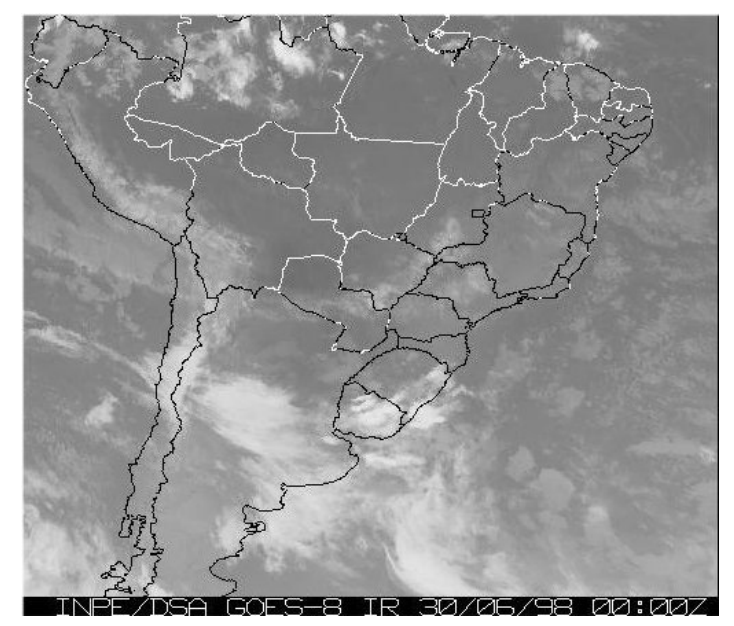

Figura 1 - Imagem do satélite geoestacionário GOES-8, no espectro infravermelho, para o dia 30 de junho de 1998, às 0000 UTC. 


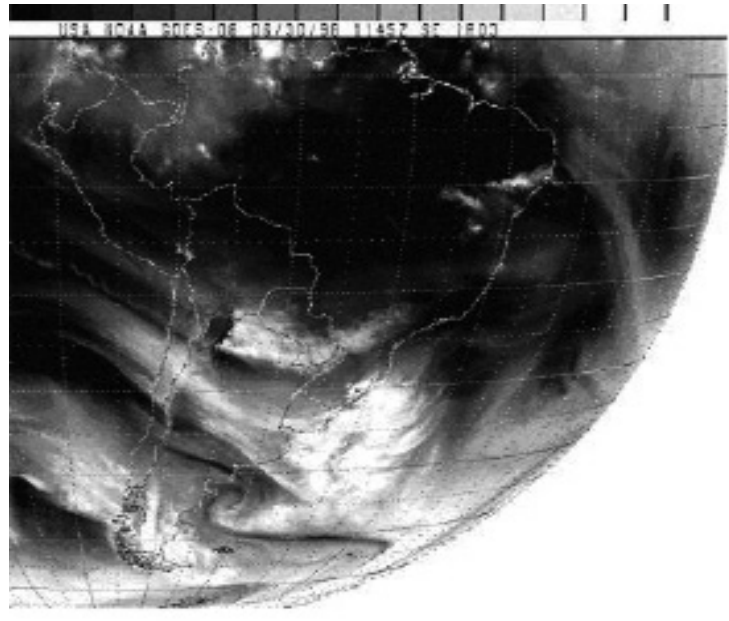

Figura 2 - Imagem no espectro do vapor d'água, para o dia 30 de junho de 1998, às 1145 UTC;

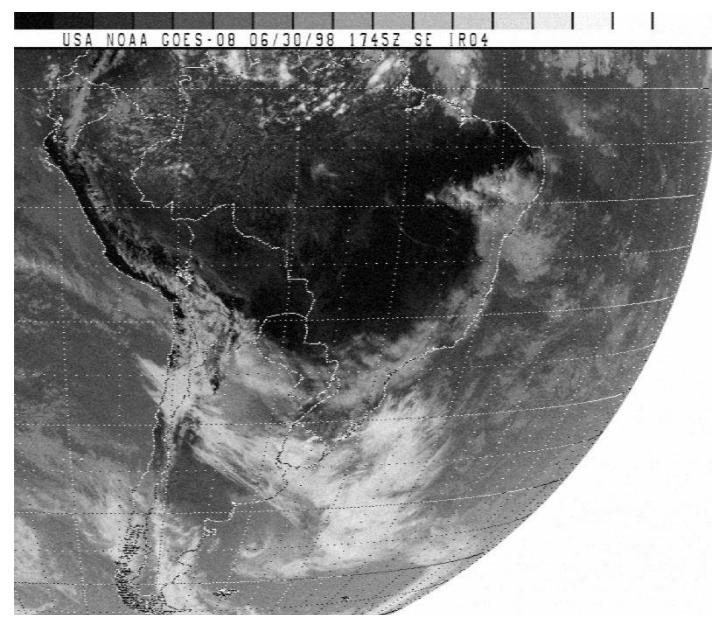

Figura 3 - Imagem do satélite GOES-8, no espectro infravermelho, para o dia 30 de junho de 1998, às 1745 UTC.

subtropical do Atlântico, cujas isóbaras apresentavam curvatura ciclônica na região onde se encontrava definida a frente quente. $\mathrm{O}$ vórtice ciclônico observado na imagem de satélite das 0000 UTC, do dia 30.06.98, com o qual estava associada a frente quente em estudo, não podia ser observado no campo de pressão ao nível médio do mar, pois o ciclone estava em seu estágio inicial anticiclones, nos oceanos Pacífico e Attântico. Todavia, neste campo próximo da costa leste da América do Sul na latitude de, aproximadamente, $40^{\circ} \mathrm{S}$ é observada uma região com pressão relativamente baixa entre os dois anticiclones, nos oceanos Pacífico e Atlântico.

Observa-se um centro isalobárico negativo no campo de tendência (12 horas) de pressão a partir de 0000 UTC de 30.06.98 (Figura 5), na região onde estava localizada a frente quente, estando os valores mais negativos de tendência (<-6 $\mathrm{hPa}$ ) localizados ao sul da mesma. Todavia, ao longo da banda

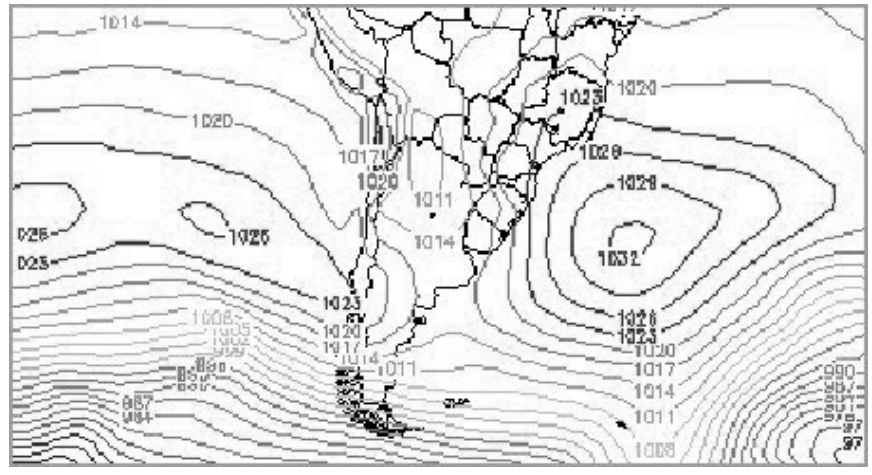

Figura 4 - Campo de pressão reduzida ao nível médio do mar para 30 de junho de 1998, às 0000 UTC.

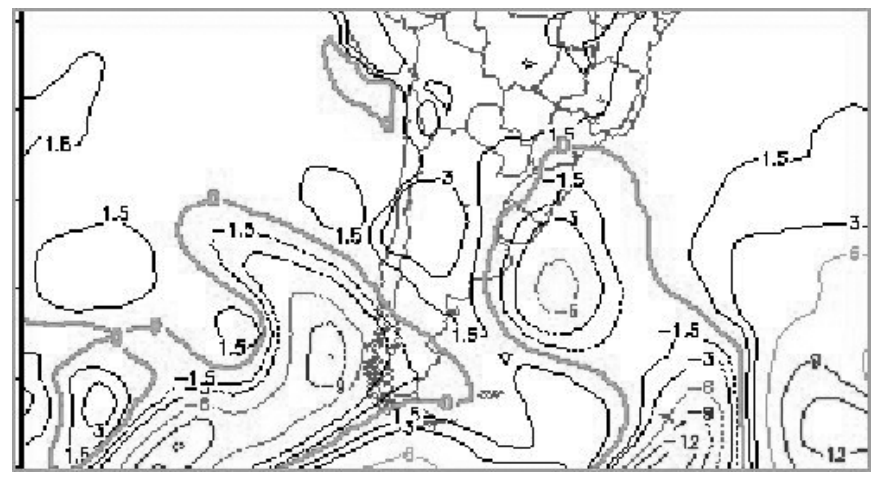

Figura 5 - Tendência de pressão, para o dia 30 de junho de 1998, às 1200 UTC, a partir das 0000 UTC desse dia.

frontal quente, a tendência de pressão tinha valores negativos significativos, variando aproximadamente, de $-1,5$ a $-4,5$ $\mathrm{hPa} / 12$ horas.

Analisando-se os campos de geopotencial para os baixos níveis (1000, 850 e $700 \mathrm{hPa}$ - não mostrados), a característica que chama atenção é que nestes campos, assim como no de pressão, não era observada a existência da zona frontal quente em estudo. $\mathrm{Na}$ região onde a frente quente era observada na imagem, existia circulação anticiclônica nos três níveis mencionados. No nível de $500 \mathrm{hPa}$ (Figura 6) ainda não se observava uma concentração das isolinhas de geopotencial. Somente a partir de $300 \mathrm{hPa}$ é que o campo de geopotencial (Figura 7), juntamente com as linhas de corrente e a posição da corrente de jato (seção 3.4) evidenciam a presença de uma zona frontal.

As isolinhas de altura geopotencial em $500 \mathrm{hPa}$ apresentavam fortes gradientes ao sul da nebulosidade da frente quente. Na região da frente em estudo existia uma crista no nível de $500 \mathrm{hPa}$ e nos níveis acima e, em baixos níveis, a alta subtropical do Atlântico (conforme discussão anterior).

Os ciclones extratropicais que são observados na região da América do Sul podem ser originados, principalmente, por 


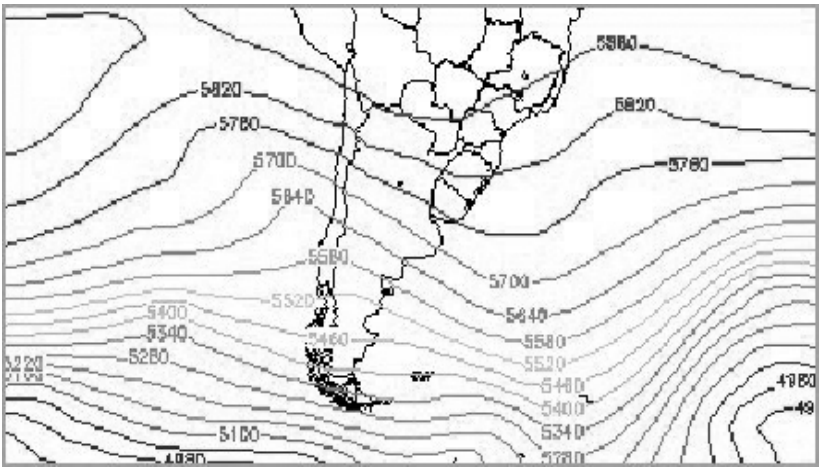

Figura 6 - Altura geopotencial para o nível de $500 \mathrm{hPa}$ no dia 30 de junho de 1998, às 0000 UTC.

instabilidade baroclínica e pelo efeito de montanha (Gan e Rao, 1991). Funatsu (2000) estudou um caso de vórtice ciclônico de altos níveis que atravessou os Andes e a partir daí ocorreu uma ciclogênese sobre a América do Sul. A autora concluiu que houve notável influência da Cordilheira dos Andes na formação do ciclone à superfície. Num campo de altura geopotencial em $400 \mathrm{hPa}$ (dados NCEP) apresentado por ela, observa-se a presença de um ciclone (isolinha de altura geopotencial fechada). No presente trabalho, embora tenhamos também usado dados do NCEP (ou seja, com a mesma resolução), não foi possível associar a presença do vórtice ciclônico observado na imagem de satélite das 0000 UTC (Figura 1) com um ciclone em nenhum dos níveis analisados. Assim, pela análise feita, não se pode concluir que houve influência de um Vórtice Ciclônico de Altos Níveis (VCAN) sobre a situação ao nível do mar.

\subsubsection{Análise dos campos de temperatura e umidade}

No campo de temperatura em $850 \mathrm{hPa}$ (Figura 8) observa-se uma língua de ar quente, que se estende desde o interior da América do Sul até o Oceano Atlântico, a leste da Argentina. Esta língua de ar quente aparece, também, no campo de temperatura de $700 \mathrm{hPa}$. Nota-se, ainda nas isotermas para $850 \mathrm{hPa}$, que elas se apresentam paralelas à frente quente, a qual tem curvatura anticiclônica, conforme observado nas imagens de satélite. O gradiente de temperatura nesta frente, em $850 \mathrm{hPa}$, é de, aproximadamente, $5^{\circ} \mathrm{C} / 500 \mathrm{~km}$. Para efeito de comparação, Bluestein (1993) cita que um valor de 10K/100 $\mathrm{km}$ é um gradiente forte associado a uma frente.

Desde a superfície até $700 \mathrm{hPa}$, os valores da umidade relativa estavam em torno de $80 \%$ na região da frente quente. Em $500 \mathrm{hPa}$, o ar já se apresentava seco, sendo $60 \%$ o valor máximo da umidade relativa.

Para se ter uma idéia da quantidade de umidade disponível em toda a camada, apresenta-se na Figura 9 o campo de água precipitável. Uma análise deste campo mostra que sobre a maior

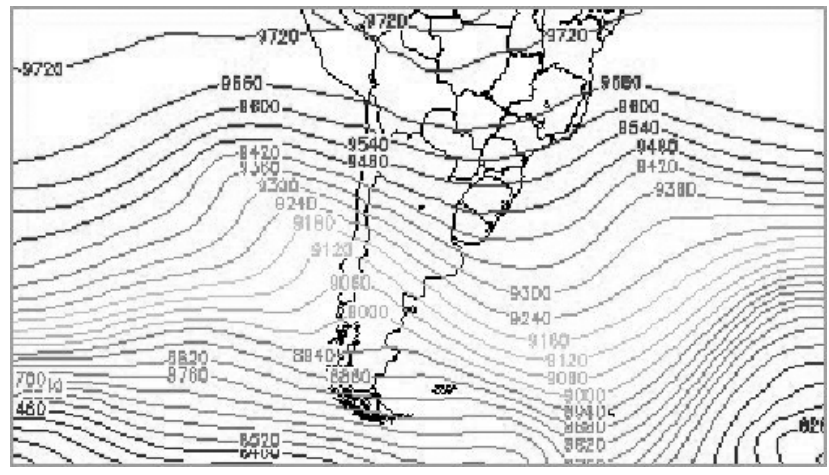

Figura 7 - Altura geopotencial para o nível de $300 \mathrm{hPa}$, no dia 30 de junho de 1998, às 0000 UTC.

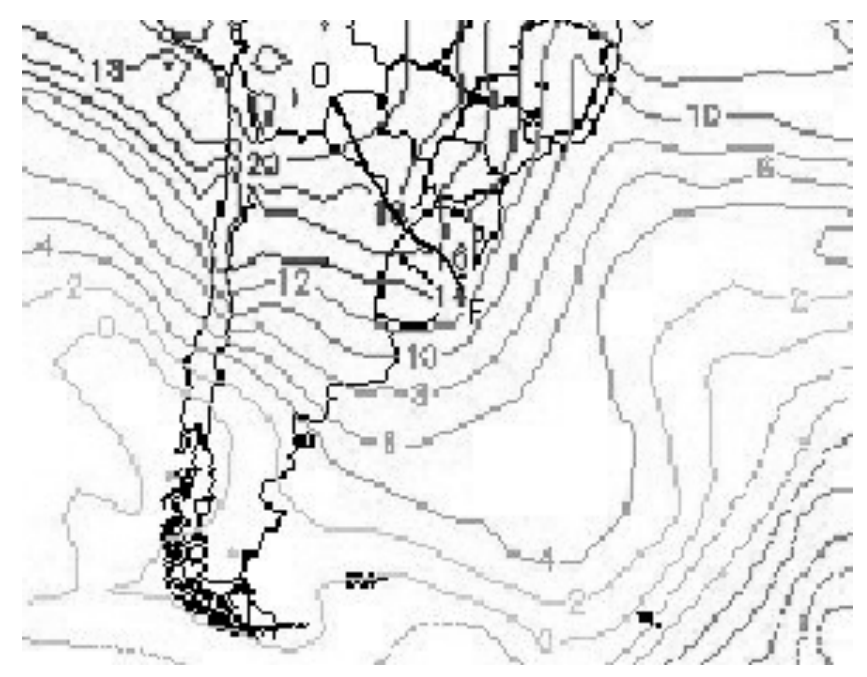

Figura 8- Temperatura em $850 \mathrm{hPa}$, para 30 de junho de 1998, 0000 UTC. A trajetória de parcelas de ar está representada pela linha contínua entre $\mathrm{O}$ e $\mathrm{F}$.

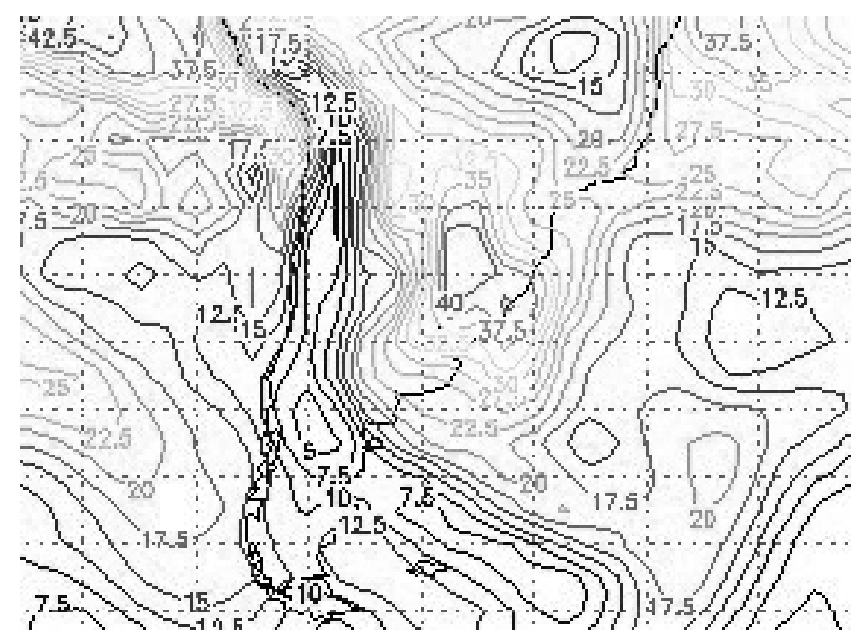

Figura 9 - Água precipitável, para o dia 30 de junho de 1998, 0000 UTC. 
parte da região onde se localizava a frente quente, a quantidade de água precipitável era maior que $35 \mathrm{~mm}$, chegando a $40 \mathrm{~mm}$ em uma pequena área no litoral do Rio Grande do Sul. Esta figura, juntamente com os dados de superfície discutidos na seção 3.2 .5 , mostra que as frentes quentes podem estar associadas a quantidades de precipitação significativas e que, por isso, deve ser estudado o seu comportamento sobre a América do Sul.

\subsubsection{Análise da divergência e vorticidade relativa}

O campo de divergência do NCEP apresenta valores positivos muito fracos (não existiam isolinhas de valor maior que 0 ), na região onde se encontrava a frente quente, no nível de $1000 \mathrm{hPa}$, no dia 30.06.98 - 0000 UTC (Figura 10). Signorini et al. (1998) também encontraram valores positivos de divergência em baixos níveis numa parte da frente quente que analisaram. Em $850 \mathrm{hPa}$, foi observada convergência fraca na região da frente quente. A única isolinha na região do sistema frontal tinha valor de $-1 \times 10^{-5} \mathrm{~s}^{-1}$. No nível de $200 \mathrm{hPa}$ (Figura 11), na mesma região, observou-se divergência, com valores que chegavam até um pouco mais de $5 \times 10^{-6} \mathrm{em}$ parte da área analisada e convergência fraca (não havia isolinha de valor negativo) no restante da área.

A região da zona frontal quente apresentava valores negativos de vorticidade relativa em $1000 \mathrm{hPa}$, na sua maior parte, porém os valores eram fracos, ou seja, a única isolinha de vorticidade tinha valor de $-1 \times 10^{-5} \mathrm{~s}^{-1}$ (Figura 12). Em $850 \mathrm{hPa}$, os valores de vorticidade variavam entre um pouco maiores que 0 e um pouco menores que 0 (não havia nenhuma isolinha de vorticidade diferente de 0 passando pela região da zona frontal quente). Em $500 \mathrm{hPa}$ os valores de vorticidade eram positivos, variando entre 0 e $2 \times 10^{-5} \mathrm{~s}^{-1}$.

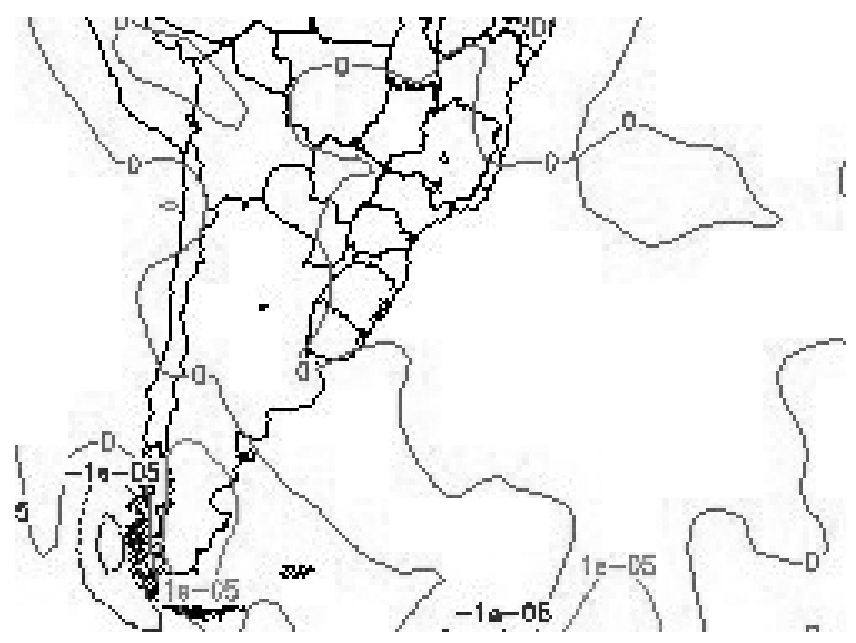

Figura 10 - Divergência horizontal em $1000 \mathrm{hPa}$, para o dia 30 de junho de 1998, às 0000 UTC.

\subsubsection{Linhas de corrente e isotacas}

Em 1000, 850 e $700 \mathrm{hPa}$, as linhas de corrente (não mostradas) apresentam circulação anticiclônica na região da frente quente, associada com a presença do anticiclone subtropical do Atlântico.

No nível de $500 \mathrm{hPa}$ (Figura 13), as linhas de corrente evidenciam a existência de uma zona frontal fria na região que se estende da parte norte da Argentina indo até a longitude de aproximadamente $90^{\circ} \mathrm{W}$, em cuja região pode-se observar um máximo na velocidade do vento, denotando, já neste nível, a existência de uma corrente de jato. Em 300 hPa (Figura 14), observa-se uma corrente de jato, cujo núcleo localiza-se entre 70 e $80^{\circ} \mathrm{W}$ e entre 28 e $35^{\circ} \mathrm{S}$. A oeste deste núcleo observam-se as linhas de corrente confluindo, na parte leste do cavado caracterizando a existência de uma zona frontal. Na região da frente quente verifica-se uma divergência das linhas de corrente. $\mathrm{Na}$ realidade existiam dois ramos da zona frontal em altos níveis. A frente quente em estudo estava associada ao ramo mais ao norte. Esta zonal frontal não foi observada em baixos e médios níveis. Em baixos níveis, a frente quente estava associada com

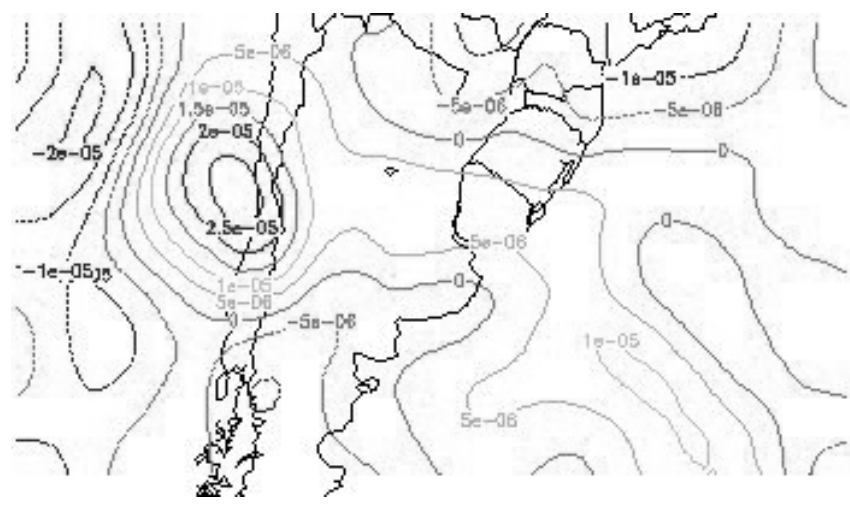

Figura 11 - Divergência horizontal em $850 \mathrm{hPa}$, para o dia 30 de junho de 1998, às 0000 UTC.

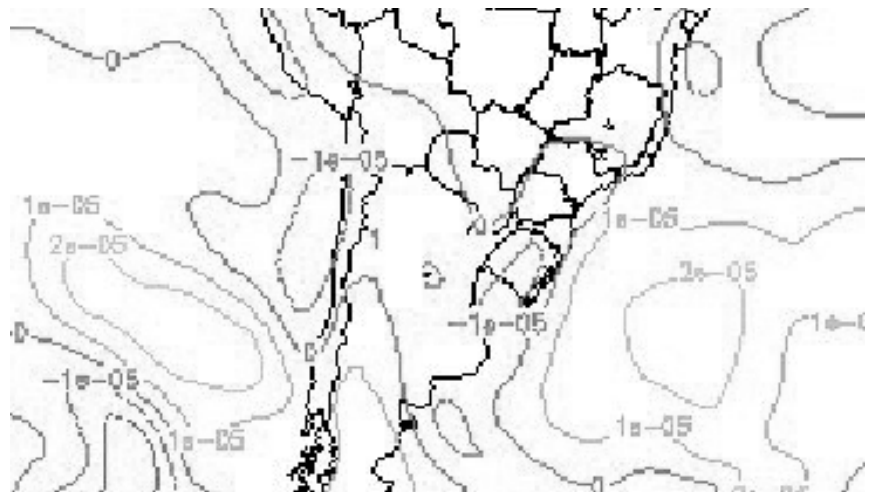

Figura 12 - Vorticidade relativa em $1000 \mathrm{hPa}$, para o dia 30 de junho de 1998, às 0000 UTC. 


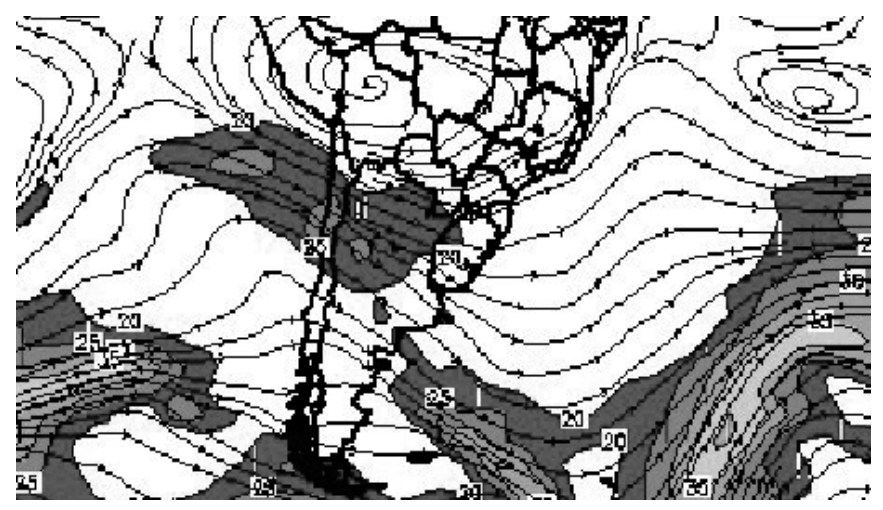

Figura 13 - Linhas de corrente e isotacas em $500 \mathrm{hPa}$, para o dia 30 de junho de 1998, às 0000 UTC.

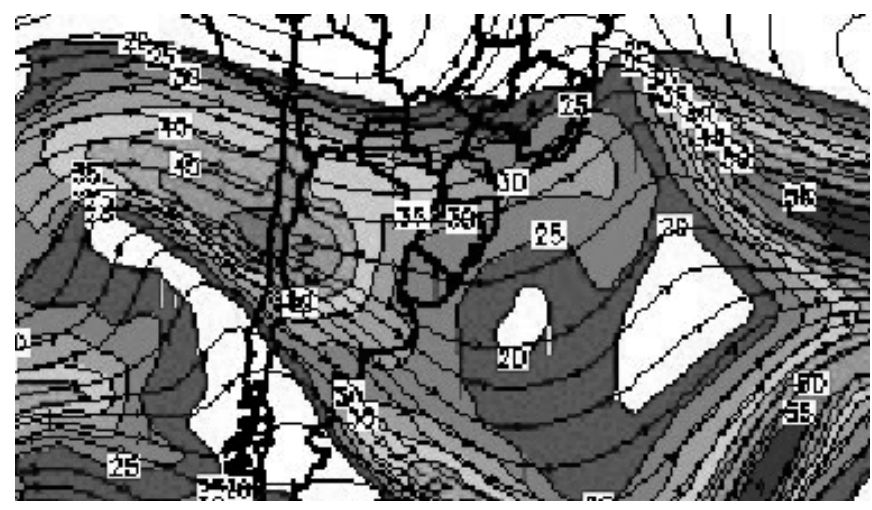

Figura 14 - Linhas de corrente e isotacas em $300 \mathrm{hPa}$, para o dia 30 de junho de 1998, às 0000 UTC,

um pequeno cavado no campo da pressão (seções 3.1.2 e 3.1.9). Já o ramo da zona frontal no ar superior, localizado mais ao sul, estava definido em toda a troposfera. Para $250 \mathrm{hPa}$ (não mostrado), a situação é bastante semelhante à de $300 \mathrm{hPa}$, sendo verificada, também neste nível, uma divergência das linhas de corrente na região da frente quente, com a diferença de que os ventos são mais fortes (a isotaca de maior valor no núcleo da corrente de jato era de $55 \mathrm{~ms}^{-1}$ ). A posição da corrente de jato neste nível mostra um núcleo localizado entre 20 e $30^{\circ} \mathrm{S}$, com a entrada sobre o Oceano Pacífico e saída próximo à região de Córdoba, na Argentina.

\subsubsection{Trajetórias}

No campo de temperatura em 1000 hPa (Figura 15), é mostrada a trajetória da parcela neste nível, que foi de, aproximadamente $1100 \mathrm{~km} \mathrm{em} 30$ horas, desde as 1800 UTC do dia 28 de junho até as 0000 UTC do dia 30 de junho. O início desta trajetória deu-se no Paraguai. Inicialmente a parcela deslocou-se para sul e depois para sudeste, até atingir o litoral sul do Rio Grande do Sul. Em $850 \mathrm{hPa}$, o deslocamento total da parcela foi de $1800 \mathrm{~km}$, desde o noroeste do Paraguai, considerando o mesmo período analisado para o nível de 1000 $\mathrm{hPa}$. Esta trajetória pode ser observada na Figura 8, juntamente com o campo de temperatura no nível de $850 \mathrm{hPa}$. A direção do deslocamento foi para sudeste durante todo o período. Para 700 $\mathrm{hPa}$ (Figura 16) foi encontrado um deslocamento em torno de $1400 \mathrm{~km}$, sendo a trajetória também de noroeste para sudeste, como nos dois níveis anteriormente mencionados. Em $500 \mathrm{hPa}$ (Figura 17) a parcela deslocou-se por uma distância aproximada de $1860 \mathrm{~km}$, no período de 30 horas, tendo como ponto de partida o Oceano Pacífico $\left(26^{\circ} \mathrm{S}, 72^{\circ} \mathrm{W}\right)$, sendo a direção do deslocamento também para sudeste.

Estas trajetórias nos quatro níveis mostram que houve um deslocamento de ar vindo de regiões mais quente para a área em estudo, o que pode ser comprovado na próxima seção.

\subsubsection{Advecção de Temperatura}

Foi calculada a advecção térmica na região da frente quente (litoral sul do Rio Grande do Sul) no dia 30.06.98,

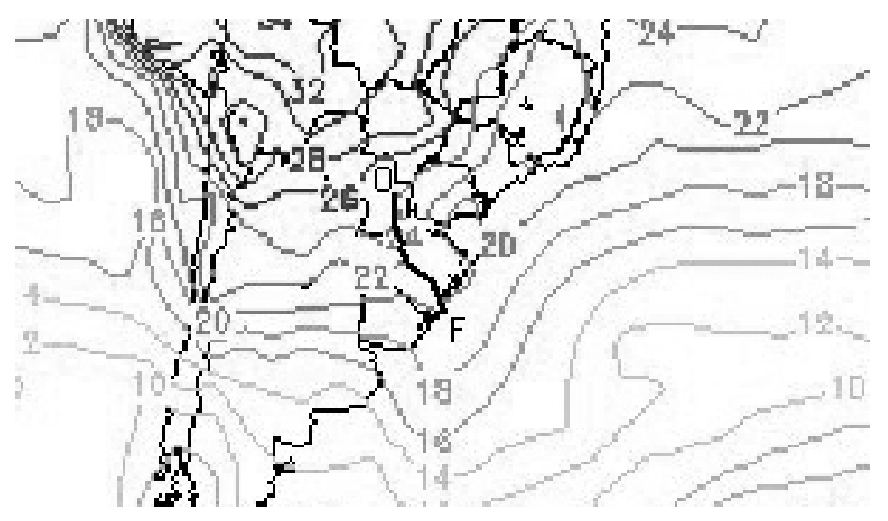

Figura 15 - Temperatura em $1000 \mathrm{hPa}$, para o dia 30 de junho de 1998, às 0000 UTC. A linha contínua entre as letras O (origem) e F (final) representa a trajetória da parcela de ar num período de 30 horas.

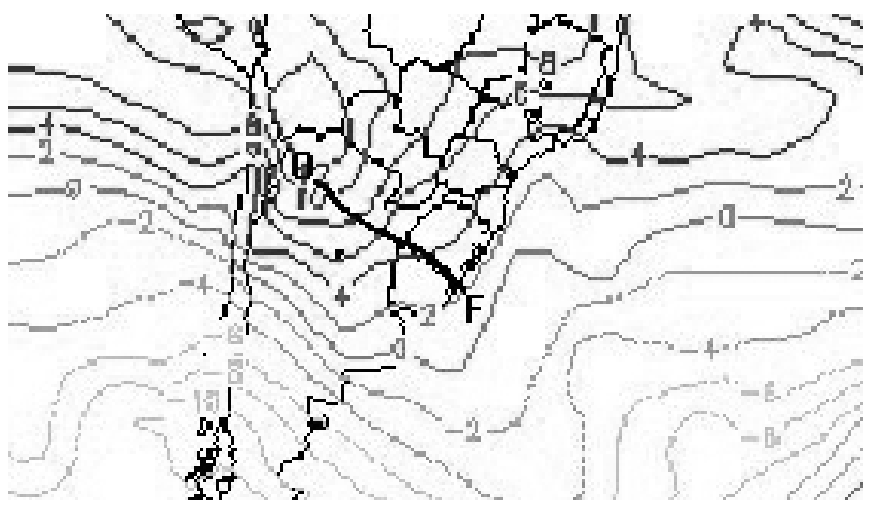

Figura 16 - Temperatura em $700 \mathrm{hPa}$, para o dia 30 de junho de 1998, às 0000 UTC. A linha contínua entre as letras $\mathrm{O}$ (origem) e F (final) representa a trajetória da parcela de ar num período de 30 horas. 


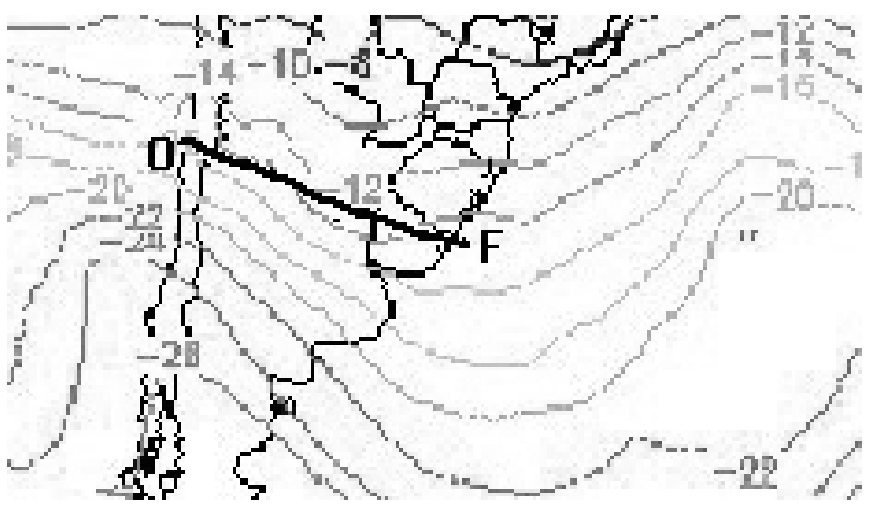

Figura 17 - Temperatura em $500 \mathrm{hPa}$, para o dia 30 de junho de 1998, às 0000 UTC. A linha contínua entre as letras $\mathrm{O}$ (origem) e F (final) representa a trajetória da parcela de ar num período de 30 horas.

às 0000 UTC, usando-se o método da trajetória da parcela. No nível de $1000 \mathrm{hPa}$, o cálculo da advecção de temperatura forneceu uma advecção de ar quente com valor de $4,5{ }^{\circ} \mathrm{C}$ no período de 30 horas mencionado no item anterior (de 28.06.98, às 1200 UTC até 0000 UTC de 30.06.98). Também nos níveis de $850 \mathrm{hPa}$ e de $700 \mathrm{hPa}$ foi obtida advecção de ar quente, com valores de $7{ }^{\circ} \mathrm{C}$ e de $8^{\circ} \mathrm{C}$ em 30 horas, respectivamente. Já no nível de $500 \mathrm{hPa}$, o valor de advecção térmica obtido usando-se a trajetória da parcela foi muito pequeno. Os valores obtidos indicam uma advecção significativa de ar quente em baixos níveis (até $700 \mathrm{hPa}$ ) na região em estudo, o que concorda com a literatura; por exemplo, Zwatz-Meise (1990), afirma que um parâmetro básico em conexão com frentes quentes é a advecção quente.

\subsubsection{Dados de Radiossondagem}

Pelas curvas de $\mathrm{T}$ e $\mathrm{T}_{\mathrm{d}}$ plotadas no diagrama termodinâmico para Porto Alegre, para o dia 30.06.98, 0000 UTC (Figura 18), verifica-se que o ar encontrava-se instável, possibilitando o desenvolvimento de nuvens cumulus que, em algumas localidades do Rio Grande do Sul, cresceram até o estágio de cumulunimbus, conforme será mostrado na seção 3.1.9. Nos dados de ventos plotados no mesmo diagrama, nota-se que, a partir de $850 \mathrm{hPa}$, o giro do vento com a altura ocorre no sentido anti-horário, ou seja, denota a presença de uma frente quente, de acordo com Lima (1985).

Na Tabela 1 apresentam-se os valores obtidos dos cálculos de energia de instabilidade, para alguns municípios do Rio Grande do Sul.

Observa-se na Tabela 1 que, por exemplo, em Torres às 0000 UTC nos baixos níveis (até $740 \mathrm{hPa}$ ) foi encontrada energia negativa e acima deste nível, até $400 \mathrm{hPa}$, obteve-se energia positiva, indicando assim que o levantamento do ar

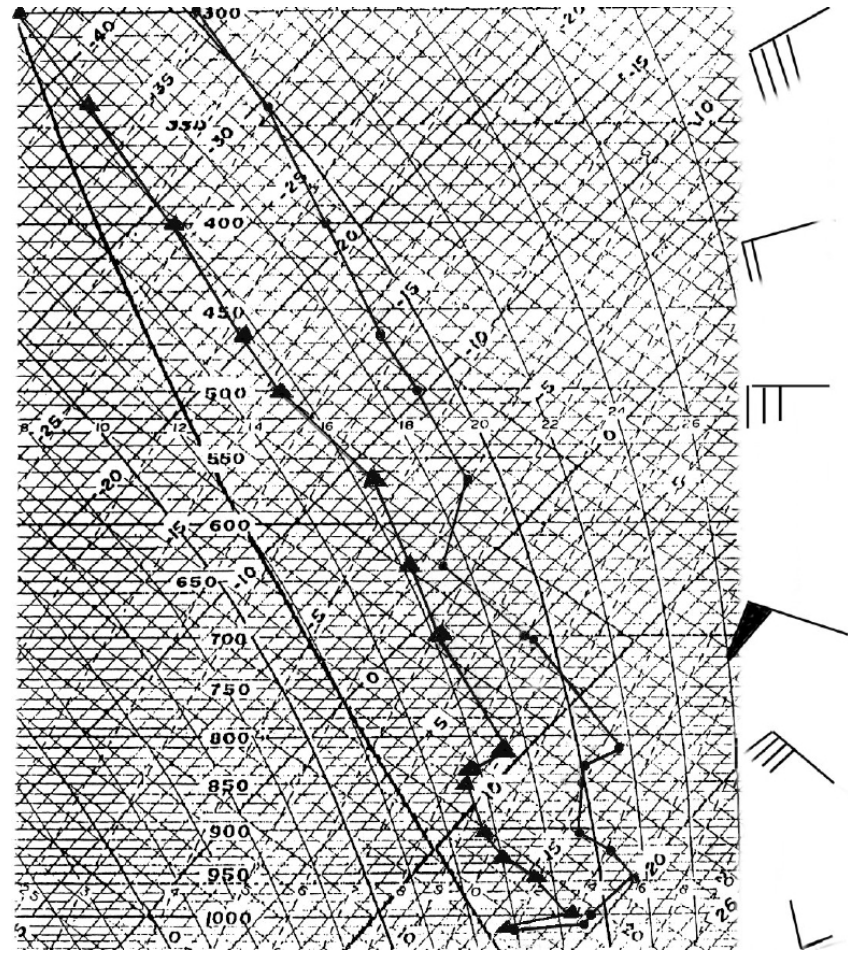

Figura 18 - Distribuição vertical de temperatura (círculos) e de temperatura do ponto de orvalho (triângulos) em Porto Alegre, para o dia 30 de junho de 1998, às 1200 UTC. Os vetores vento estão plotados no lado direito do diagrama.

Tabela 1 - Energia de Instabilidade calculada para o dia 30 de junho de 1998.

\begin{tabular}{c|c|c|c|c}
\hline Local & \multicolumn{2}{|c|}{$\begin{array}{c}\text { Energia Positiva } \\
(\mathrm{J} / \mathrm{kg})\end{array}$} & \multicolumn{2}{c}{$\begin{array}{c}\text { Energia negativa } \\
(\mathrm{J} / \mathrm{kg})\end{array}$} \\
& \multicolumn{2}{|c|}{} & \multicolumn{2}{c}{} \\
\hline Torres (0000) & $\begin{array}{c}\text { Camada } \\
710-400 \mathrm{hPa}\end{array}$ & $\begin{array}{c}\text { valor } \\
105\end{array}$ & $\begin{array}{c}\text { Camada } \\
920-740\end{array}$ & $\begin{array}{c}\text { Valor } \\
77\end{array}$ \\
& & & & \\
\hline Torres (1200) & $710-410 \mathrm{hPa}$ & 84 & $1000-720$ & 59 \\
& & & $400-300$ & 86 \\
\hline Porto Alegre (1200) & $960-880 \mathrm{hPa}$ & 18 & $880-670$ & 66 \\
& $670-410 \mathrm{hPa}$ & 152 & & \\
\hline Sta. Vitória do & $790-355 \mathrm{hPa}$ & 767 & $1000-790$ & 137 \\
Palmar (0000) & & & & \\
\hline
\end{tabular}

estava favorecido nos níveis acima de $740 \mathrm{hPa}$. A energia de instabilidade representa o trabalho feito sobre a parcela pelo ambiente, conforme a parcela é acelerada para cima. É importante ressaltar que a existência de energia de instabilidade é somente uma condição necessária para a convecção; a quantidade de energia de instabilidade afeta o caráter da convecção que ocorre se ela, de fato, for iniciada (Bluestein, 1993). O desenvolvimento da convecção sobre a camada superficial estável foi discutida 
em (Fedorova e Khan, 1999), onde foi apresentada a análise de desenvolvimento de um CCM. No presente caso, a convecção foi disparada, pois, de acordo com dados do Oitavo Distrito de Meteorologia, do INMET, foi registrada a ocorrência de nuvens $\mathrm{Cb}$ em Torres, na observação meteorológica realizada no dia 30.06.98, às 1200 UTC.

Também foram calculados vários índices de instabilidade para as localidades que aparecem na Tabela 1 , os quais são apresentados na Tabela 2.

Pode-se observar na Tabela 2 que nas quatro localidades para as quais foram calculados os índices existiam chances de formação de trovoadas, considerando-se pelo menos o índice K. Quando o valor deste índice é maior do que 25, existem chances de formação de nuvens cumulonimbus $(\mathrm{Cb})$. Em Santa Vitória do Palmar, que fica localizada na parte meridional do Rio Grande do Sul, todos os índices mostraram valores favoráveis à ocorrência de trovoada e nos dados do boletim sinótico das 0000 UTC do dia 30 de junho de 1998 comprovou-se a ocorrência de $\mathrm{Cb}$, com a presença de trovoada no tempo presente e no tempo passado.

\subsubsection{Análise de Mesoescala}

A carta de superfície das 0000 UTC (Figura 19) construída para o Rio Grande do Sul mostra um meso-cavado com eixo sudoeste-nordeste sobre o estado. Pelos dados plotados, observa-se que nas três horas anteriores ao horário da observação a tendência de pressão foi nula em várias estações do Rio Grande do Sul. A maior parte deste estado encontrava-se sob a massa de ar quente tropical (setor quente do ciclone). Nos dados plotados, pode-se observar também que, nas estações localizadas na costa do Rio Grande do Sul, os ventos eram, predominantemente, de leste ou de nordeste, o que é característico de uma situação pré-frontal quente. A estação de Santa Vitória do Palmar, no extremo Sul do Rio Grande

Tabela 2 - Índices de Instabilidade Atmosférica para o dia 30 de junho de 1998.

\begin{tabular}{l|c|c|c}
\hline \multicolumn{1}{c|}{$\begin{array}{c}\text { Localidade/ } \\
\text { Horário }\end{array}$} & $\begin{array}{c}\text { Showalter } \\
\text { (IS) }\end{array}$ & $\mathrm{K}$ & $\begin{array}{c}\text { Totals } \\
\text { (TOT) }\end{array}$ \\
\hline Torres (0000) & 4,0 & 27,5 & 44,0 \\
Torres (1200) & 3,7 & 28,5 & 44,0 \\
$\begin{array}{l}\text { Porto Alegre } \\
\text { (1200) }\end{array}$ & 3,5 & 30,2 & 43,7 \\
$\begin{array}{l}\text { Sta. Vitória do } \\
\text { Palmar (0000) }\end{array}$ & $-0,5$ & 34,4 & 50,6 \\
\end{tabular}

do Sul, registrou nuvens cumulunimbus neste horário. Esta estação também apresentou ocorrência de trovoadas no tempo passado. Algumas estações localizadas no setor quente do ciclone extratropical registraram nevoeiro no horário da observação.

Nas cartas para 0000 e 1200 UTC (não mostradas) foi observada convergência de ventos na região de Porto Alegre, e neste último horário observaram-se trovoadas nesta cidade.

Às 1200 UTC, já havia aumentado a região de precipitação ligada à frente quente. As estações de Santa Vitória do Palmar, Porto Alegre e Torres apresentaram ocorrência de nuvens $\mathrm{Cb}$. Na observação deste horário, as estações mais próximas da costa do Rio Grande do Sul apresentaram chuva no tempo presente ou no tempo passado, ou em ambos. Duas registraram trovoadas no tempo passado. Dentro do setor quente, foram observados nevoeiros, nuvens estratiformes e alguma chuva fraca.

No dia 30.06.98, às 1800 UTC (carta não mostrada), o cavado de mesoescala continuava bem definido sobre o Rio Grande do Sul. O céu ainda encontrava-se encoberto na maior parte das regiões, tendo sido registrada chuva ou trovoada em algumas estações. Neste horário, a frente quente já não se encontrava mais sobre o Rio Grande do Sul, o qual estava quase inteiramente (exceto o setor mais meridional) sob a influência do setor quente do ciclone, conforme pode ser constatado na imagem infravermelha das 1745 UTC. A direção do vento mudou em praticamente todas as estações do estado. Neste horário, a estação de Santa Vitória já apresentava nuvens associadas com uma frente fria. Em Rio Grande o vento passou a soprar do norte e em Encruzilhada do Sul, do noroeste. Nota-se que neste horário, algumas estações do RS registraram nevoeiro no tempo presente ou no tempo passado.

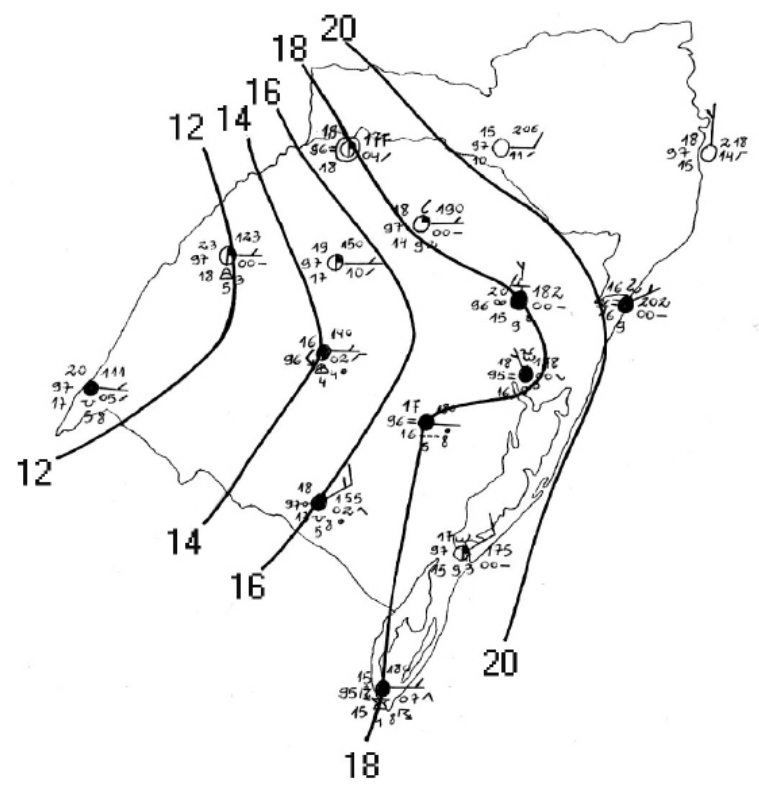

Figura 19 - Carta de superfície para o dia 30 de junho de 1998, às 0000 UTC. 


\subsection{Situação de $\mathbf{1}^{\circ}$ de outubro de 1999}

No dia anterior ao da ocorrência da frente quente em estudo, ou seja, no dia 30.09.99, observou-se na carta de linhas de corrente para $850 \mathrm{hPa}$ (não mostrada), uma corrente de ar vinda da região central da América do Sul, a qual chegava até a região norte da Argentina e o Rio Grande do Sul. Analisando também o campo de temperatura para o mesmo nível, verificava-se que a corrente originava-se numa região de ar quente e, portanto, as regiões anteriormente mencionadas foram supridas com este ar. Na imagem das 1445 UTC do dia 30 de setembro de 1999 (não mostrada) já eram observadas nuvens cirrustratus com curvatura anticiclônica na região central da Argentina, indicando, de acordo com Fedorova e Bakst (1999), a existência de adveccção de ar quente.

\subsubsection{Análise das imagens de satélite}

$\mathrm{Na}$ imagem de 30 de setembro de 1999, às 2045 UTC (não mostrada), observa-se na região central da Argentina nebulosidade cirrustratus com curvatura anticiclônica, já começando a atingir o Uruguai.

Às 0245 UTC, de $1^{\circ}$ de outubro de 1999, a região com nebulosidade cirrustratus aumentou e já tomava conta de todo o Uruguai e boa parte do Rio Grande do Sul. Entre as 0245 e as 0845 UTC (imagens não mostradas) observou-se que a nebulosidade tornou-se mais densa no noroeste do Rio Grande do Sul, e sobre o centro de SC observaram-se nuvens convectivas. Na imagem das 0845 UTC nota-se que a frente quente já estava começando a se definir, e na imagem no canal do infravermelho das 1145 UTC (Figura 20), ela já estava definida e influenciava o tempo nos estados do Rio Grande do

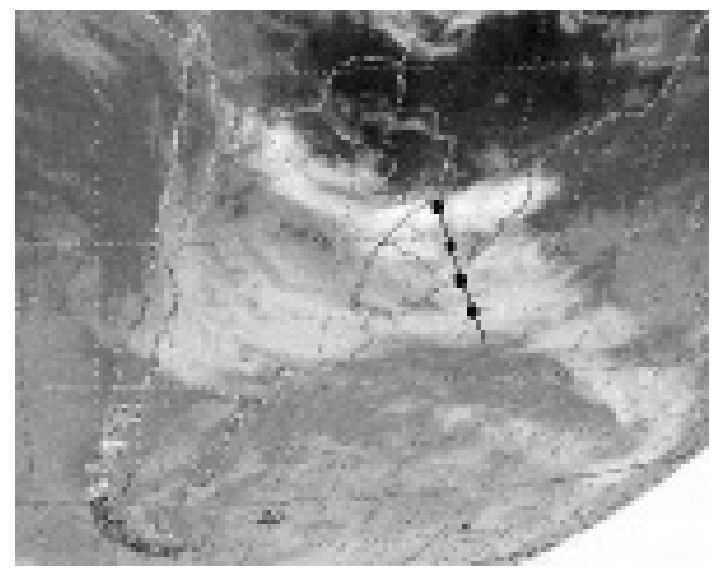

Figura 20 - Imagem de satélite no espectro infravermelho, para o dia 1o. de outubro de 1999, às 1145 UTC. A linha com pontos representa a direção ao longo da qual foi construída a seção vertical da Figura 27.
Sul e de Santa Catarina. Em algumas regiões do Rio Grande do Sul, além das nuvens estratiformes, observavam-se também nuvens convectivas.

A interpretação da imagem na Figura 20, de acordo com Anderson et al. (1973), mostra o centro do vórtice ainda sobre o oceano Pacífico e a frente quente estendendo-se desde a região nordeste da Argentina, atravessando a fronteira no sudoeste do Rio Grande do Sul e atingindo o norte de Santa Catarina. Deve-se enfatizar que o centro do vórtice não estava bem definido na imagem mostrada na Figura 20.

\subsubsection{Análise dos campos da pressão, da tendência de pressão e da altura geopotencial}

No campo da pressão reduzida ao nível do mar das 1200 UTC do dia $1^{\circ}$ de outubro de 1999 (Figura 21), a frente podia ser localizada na região de colo entre a alta do Atlântico e a alta polar, e entre a baixa continental (térmica), localizada na parte centro-oeste da América do Sul, e um ciclone extratropical, localizado no Atlântico.

Próximo à costa oeste da América do Sul, verifica-se na Figura 21 a presença de um cavado, ao qual está associado o centro do vórtice na imagem de satélite (Figura 20).

No campo da tendência da pressão para 12 horas, a partir das 0000 UTC (não mostrado), podia-se observar valores negativos na maior parte da região abrangida pela frente quente, atingindo, no nordeste do RS e em Santa Catarina, valores abaixo de $-1,5 \mathrm{hPa}$ em 12 horas.

$\mathrm{Na}$ carta de geopotencial de $850 \mathrm{hPa}$ (não mostrada), a região onde estava localizada a frente quente também se caracterizava por uma ausência de linhas. Está bem definido nesta carta somente o cavado no Atlântico e um pouco menos definida a alta polar.

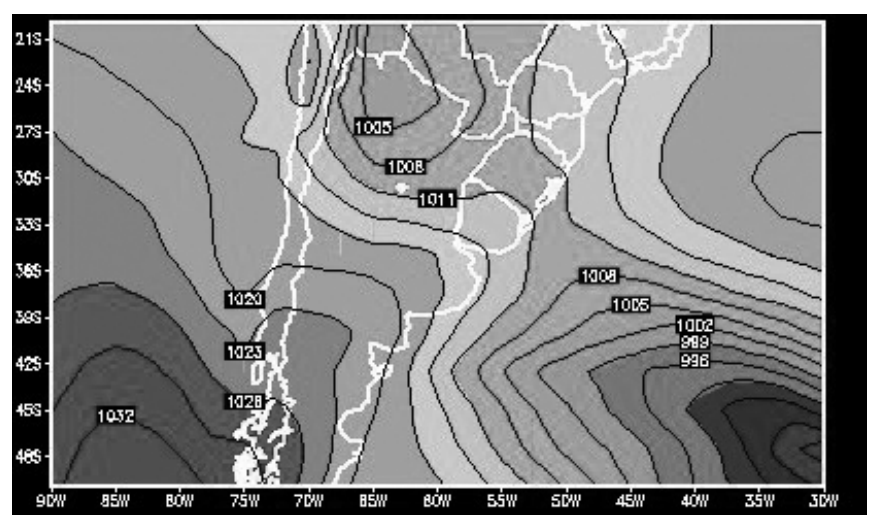

Figura 21 - Campo de pressão reduzida ao nível médio do mar, para o dia 1o de outubro de 1999, às 1200UTC. 
Já no campo de geopotencial para o nível de $700 \mathrm{hPa}$, podia-se observar o cavado no Atlântico e a alta semipermanente do Atlântico. Neste nível se define um cavado próximo à costa oeste da América do Sul, na parte central do Chile, também associado ao centro do vórtice observado na imagem de satélite.

Em $500 \mathrm{hPa}$ este cavado está bem definido sobre o Oceano Pacífico, o que, todavia, não ocorre em $200 \mathrm{hPa}$. Na região onde se observa a frente quente na imagem de satélite, as isoípsas apresentam curvatura anticiclônica no nível de 200 mb. Esta curvatura, contudo, não é acentuada, sendo que sobre o Rio Grande do Sul o escoamento é quase zonal.

Convém salientar que 12 horas antes, na configuração de altura geopotencial de $500 \mathrm{hPa}$ (não mostrada), o cavado localizado sobre o Oceano Pacífico estava bem acentuado. Verificando-se a estrutura vertical deste cavado, percebe-se que ele estava definido desde o nível de $300 \mathrm{hPa}$, apresentando uma amplitude maior em $400 \mathrm{hPa}$ e atingindo o nível da superfície, com uma pequena inclinação do seu eixo vertical para oeste entre os níveis de 500 e $850 \mathrm{hPa}$. Comparando-se a região de nebulosidade observada na imagem das 1145 UTC (Figura 20) com a localização do cavado nos níveis abaixo de $700 \mathrm{hPa}$, nota-se que a referida nebulosidade estava associada à presença do cavado.

\subsubsection{Análise dos Campos de Temperatura, Umidade Relativa e Água Precipitável}

O campo de temperatura em $1000 \mathrm{hPa}$ para o horário das 1200 UTC (Figura 22) mostra uma língua de ar quente no centro da América do Sul, a qual se estende sobre o Rio Grande do Sul, chegando até o Oceano Atlântico, assim como foi observado no primeiro caso estudado. No norte do Paraguai a temperatura passa dos $32^{\circ} \mathrm{C}$. Já sobre a Argentina, observa-se uma massa de ar frio, existindo uma concentração maior de isotermas na parte

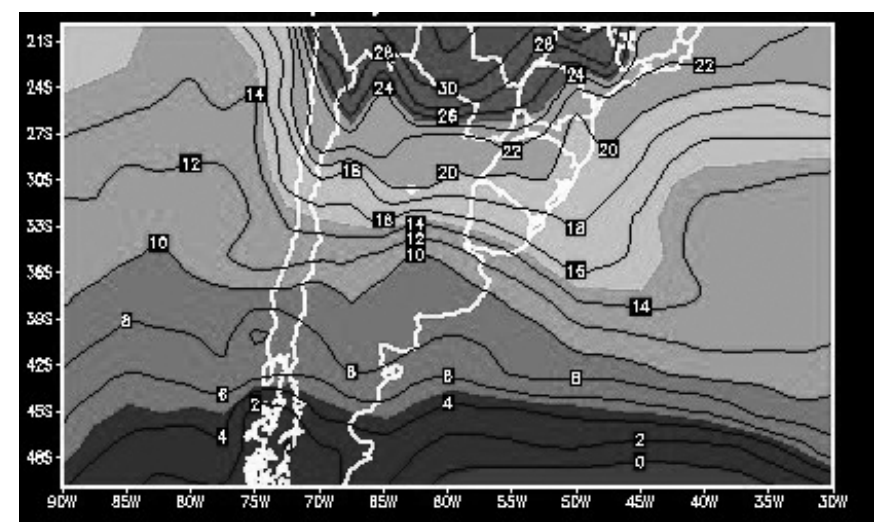

Figura 22 - Campo de temperatura do nível de $1000 \mathrm{hPa}$, para o dia $1^{\circ}$ de outubro de 1999 , às 1200 UTC. centro-leste da Argentina e sul do Uruguai.

Até o nível de $500 \mathrm{hPa}$ (campos não mostrados), pode-se observar a massa de ar quente atingindo praticamente todo o estado do Rio Grande do Sul.

Foi observado um aumento da temperatura a partir do dia 30.09.99, às 1200 UTC até o dia 01.10.99, às 1200 UTC, em várias estações do Rio Grande do Sul. Este aumento de temperatura foi devido à advecção de ar quente.

No campo de umidade relativa para as 1200 UTC do dia 01.10.99 em $1000 \mathrm{hPa}$ (Figura 23), observa-se que na região onde se localizava a frente quente, a umidade encontrava-se acima de $70 \%$, sendo que os maiores valores foram observados no noroeste do RS e no estado de Santa Catarina. Em $500 \mathrm{hPa}$, os maiores valores de umidade relativa estavam concentrados na região central da Argentina e no Uruguai, ficando a região da frente quente com um valor máximo entre 80 e 90\%, na fronteira do RS com a Argentina.

Analisando o campo de água precipitável, para as 1200 UTC do dia $1^{\circ}$ de outubro de 1999 (Figura 24), verifica-se que na região da frente quente são encontrados valores maiores que

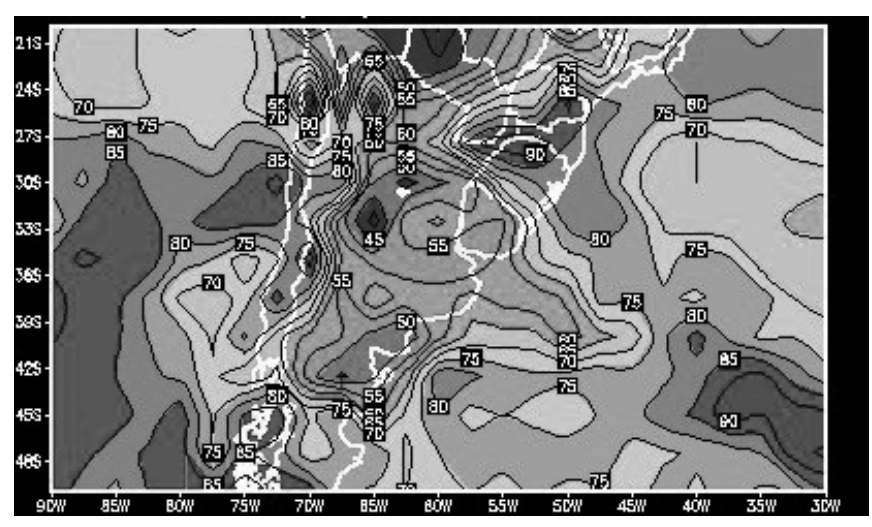

Figura 23 - Campo de umidade relativa em $1000 \mathrm{hPa}$, para o dia 10 de outubro de 1999, às 1200 UTC.

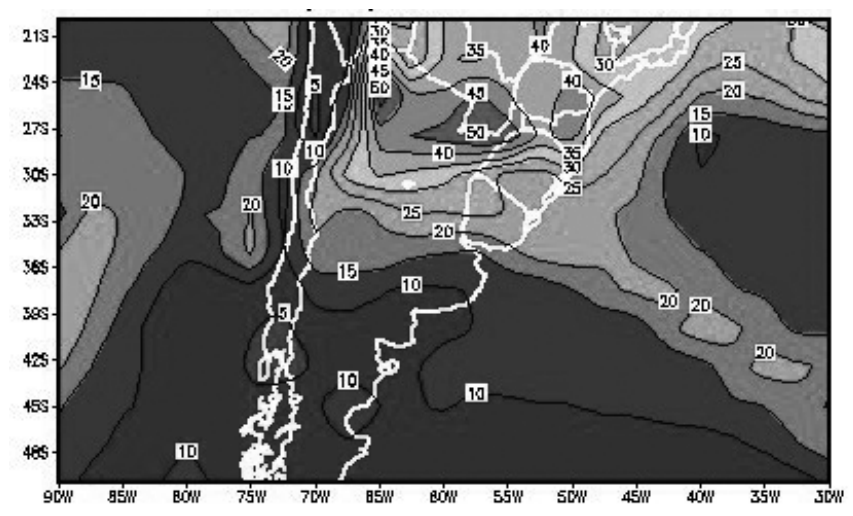

Figura 24 - Água precipitável para o dia 1o de outubro de 1999, 1200 UTC. 
$30 \mathrm{~kg} / \mathrm{m}^{2}$, o que demonstra, pela experiência sinótica, que este campo mostrava a possibilidade de ocorrência de precipitação, uma vez que valores de água precipitável, maiores do que aquele citado anteriormente, possibilitam esta situação.

\subsubsection{Linhas de corrente e isotacas}

As linhas de corrente em $925 \mathrm{hPa}$, para $1200 \mathrm{UTC}$ do dia $1^{\circ}$ de outubro de 1999 (Figura 25), mostram que a frente quente, neste nível, estava localizada numa região onde o escoamento era anticiclônico, sendo que em uma parte da região, este escoamento estava associado ao anticiclone do Atlântico e, na outra parte, ao anticiclone polar.

Em $200 \mathrm{hPa}$ (não mostrado) as linhas de corrente também mostravam escoamento anticiclônico (uma crista) sobre a região onde estava localizada a frente quente. Logo ao sul da frente quente observava-se um máximo no vento (corrente de jato). Os ventos com velocidades altas abrangiam uma região bastante ampla.

\subsubsection{Divergência e vorticidade relativa}

No campo de divergência em $925 \mathrm{hPa}$, para o dia $1^{\circ}$ de outubro de 1999, às 1200 UTC, (Figura 26) verifica-se que existia convergência na região da frente quente, sendo que o valor máximo sobre o Rio Grande do Sul era $-1 \times 10^{-5} \mathrm{~s}^{-1}$, na fronteira noroeste. Uma isolinha de valor zero passava na parte leste da fronteira dos estados do Rio Grande do Sul e de Santa Catarina. Assim, na região da frente quente localizada sobre Santa Catarina foram observados valores positivos de divergência; todavia não existiam isolinhas naquela região, ou seja, os valores estavam próximos de zero. Em $250 \mathrm{hPa}$, a maior parte da frente quente estava localizada numa região de divergência onde os valores atingiam, no máximo, $5 \times 10^{-6} \mathrm{~s}^{-1}$. Comparar-se-ão os valores de divergência encontrados neste sistema em estudo, com aqueles observados na retaguarda de numa frente fria observada no Oceano Atlântico, próximo ao litoral do Rio Grande do Sul, encontrados por Signorini et al. (1998), os quais foram: $-1,0 \times 10^{-5} \mathrm{~s}^{-1} \mathrm{em} 925 \mathrm{hPa}$ e $1,3 \times 10^{-5} \mathrm{~s}^{-1}$ em $250 \mathrm{hPa}$. Assim, verifica-se que em baixos níveis ( $925 \mathrm{hPa}$ ), os dois sistemas apresentaram o mesmo valor de convergência, enquanto que, em altos níveis $(250 \mathrm{hPa})$, a frente fria mostrou um valor maior de divergência em comparação à frente quente.

Em relação à vorticidade relativa, no nível de $1000 \mathrm{hPa}$ (Figura 27) foram verificados valores negativos baixos (módulo abaixo de $1 \times 10^{-5} \mathrm{~s}^{-1}$ ) na região da frente quente. Em $500 \mathrm{hPa}$ os valores eram um pouco maiores que $2 \times 10^{-5} \mathrm{~s}^{-1}$ positivos, assim como eram positivos também em $250 \mathrm{mb}$, com valores significativos, ou seja, um pouco maiores que $5 \times 10^{-5} \mathrm{~s}^{-1}$, na maior parte da região sob influência da frente quente. Novamente,

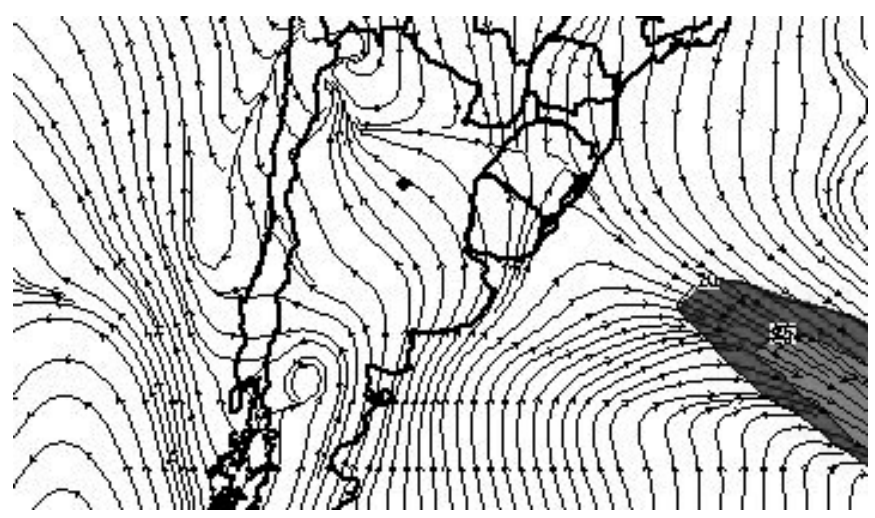

Figura 25 - Linhas de corrente e isotacas em $925 \mathrm{hPa}$, para o dia 10 de outubro de 1999, às 0000 UTC.

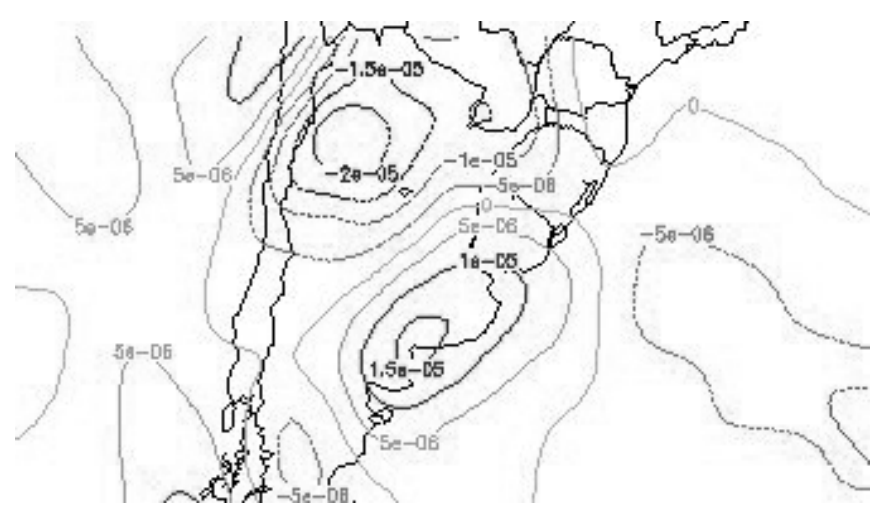

Figura 26 - Divergência horizontal em $925 \mathrm{hPa}$, para o dia 1o de outubro de 1999, às 1200 UTC.

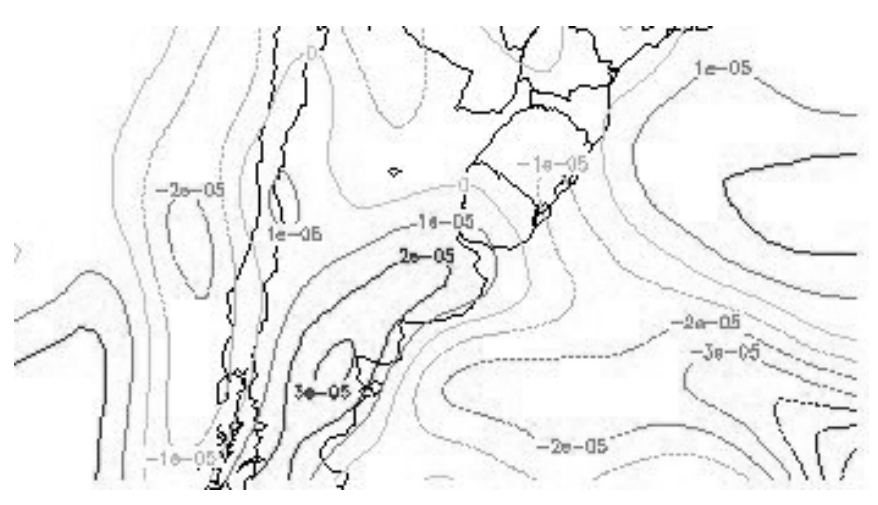

Figura 27- Vorticidade relativa em $1000 \mathrm{hPa}$, para o dia 1 o de outubro de 1999 , às 1200 UTC.

no caso da vorticidade relativa far-se-ão comparações dos valores mostrados neste trabalho com aqueles apresentados por Signorini et al. (1998) para o caso de uma frente fria. Para os níveis de 1000,500 e $250 \mathrm{hPa}$, ela encontrou os valores: $-1,0 \mathrm{x}$ $10^{-5} \mathrm{~s}^{-1}, 2 \times 10^{-5} \mathrm{~s}^{-1}$ e $2 \times 10^{-5} \mathrm{~s}^{-1}$, respectivamente, para a região na retaguarda de uma frente fria. Comparando-se os valores nos 
dois sistemas, verifica-se que nos níveis de 1000 e 500 hPa os valores eram iguais, porém em altos níveis $(250 \mathrm{hPa})$, na região da frente quente, a vorticidade anticiclônica era maior do que na retaguarda da frente fria.

\subsubsection{Seções verticais da atmosfera e Índices de Instabilidade}

Na Figura 28 é mostrada uma seção transversal vertical da atmosfera numa direção perpendicular (linha mostrada na Figura 20) à frente quente em estudo, para o dia $1^{\circ}$ de outubro de 1999. Os pontos usados para a construção da seção foram $35^{\circ} \mathrm{S}, 50^{\circ} \mathrm{W} ; 33,5^{\circ} \mathrm{S}, 51,5^{\circ} \mathrm{W} ; 31^{\circ} \mathrm{S}, 52^{\circ} \mathrm{W}$ e $28,5^{\circ} \mathrm{S}$, $54^{\circ} \mathrm{W}$. Observa-se que as isolinhas de temperatura potencial (isentrópicas) apresentam uma inclinação, principalmente acima de $850 \mathrm{hPa}$. Considerando-se que as trajetórias das parcelas de ar são essencialmente adiabáticas (Green et al, 1966), e associando-se o campo de vento à configuração apresentada ( no ponto $31^{\circ} \mathrm{S}, 52^{\circ} \mathrm{W}$, o vento era de noroeste em vários níveis), verifica-se que, em função da inclinação das isentrópicas, teria de haver movimento ascendente. Isto se explica pelo fato de que, para continuar sua trajetória ao longo da mesma superfície isentrópica, as parcelas de ar precisavam subir, conforme foi explicitado na metodologia. Consultando-se os dados sinóticos de estações próximas à região em discussão, observa-se que

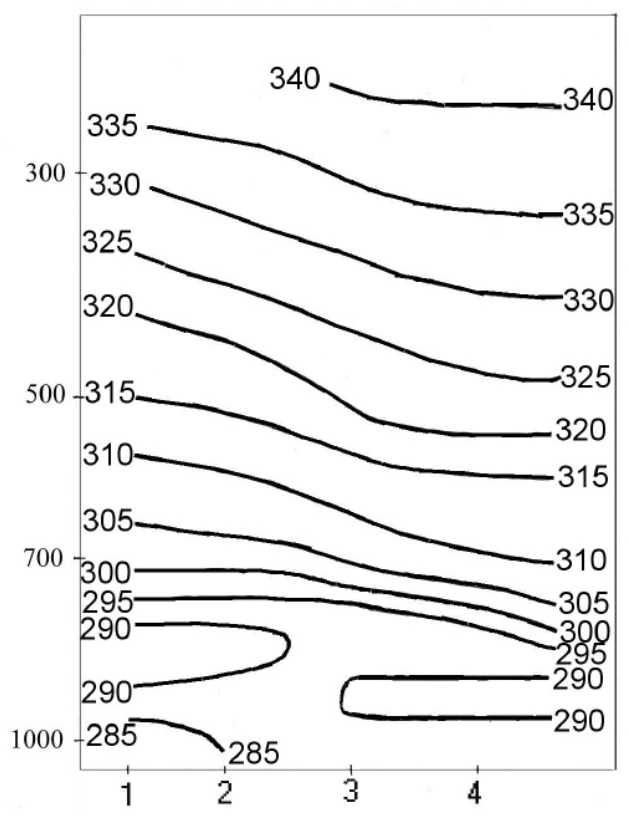

Figura 28 - Seção transversal da atmosfera na direção perpendicular à frente quente mostrada na figura 20, para o dia 1o de outubro de 1999, às 1200 UTC. Os pontos 1, 2, 3 e 4 correspondem, respectivamente, às seguintes posições geográficas: $35^{\circ} \mathrm{S}, 50^{\circ} \mathrm{W} ; 33,5^{\circ} \mathrm{S}, 51,5^{\circ} \mathrm{W} ; 31^{\circ}$ $\mathrm{S}, 52^{\circ} \mathrm{W}$ e $28,5^{\circ} \mathrm{S}, 54^{\circ} \mathrm{W}$. realmente existia movimento ascendente nesta região, uma vez que foi registrada precipitação às 1200 UTC. Outras duas seções verticais transversais perpendiculares à frente quente estudada foram construídas, e também mostravam o mesmo tipo de inclinação das linhas isentrópicas

Foram calculados vários índices de instabilidade para a estação de Porto Alegre, para o dia $1^{\circ}$ de outubro de 1999 e todos eles mostraram que não havia possibilidade de trovoadas, o que pode ser comprovado nos dados dos boletins sinóticos que registraram apenas precipitação leve em Porto Alegre no horário citado. Foram também construídos os perfis verticais de temperatura do ar e de temperatura do ponto de orvalho usando dados do modelo do NCEP para Passo Fundo (28,1 S; 52,2 W) e para Pelotas. Dos índices calculados para Passo Fundo, apenas o índice $\mathrm{K}$ mostrou um valor $(25,2)$, que indicava a possibilidade de ocorrência de trovoadas. Pelos dados do Oitavo Distrito de Meteorologia foram registradas nuvens de desenvolvimento vertical com ocorrência de trovoadas naquela localidade. Para Pelotas, nenhum dos índices apontou possibilidade de formação de trovoadas, o que está de acordo com observações de nebulosidade realizadas no Centro de Pesquisas Meteorológicas, que para este dia registram nuvens estratiformes.

\subsubsection{Análise de mesoescala}

A análise do campo da pressão sobre o Rio Grande do Sul e Santa Catarina, para o dia $1^{\circ}$ de outubro de 1999, às 1200 UTC(Figura 29) mostra um centro de alta pressão de mesoescala abrangendo as regiões nordeste do primeiro estado e sudeste do segundo.

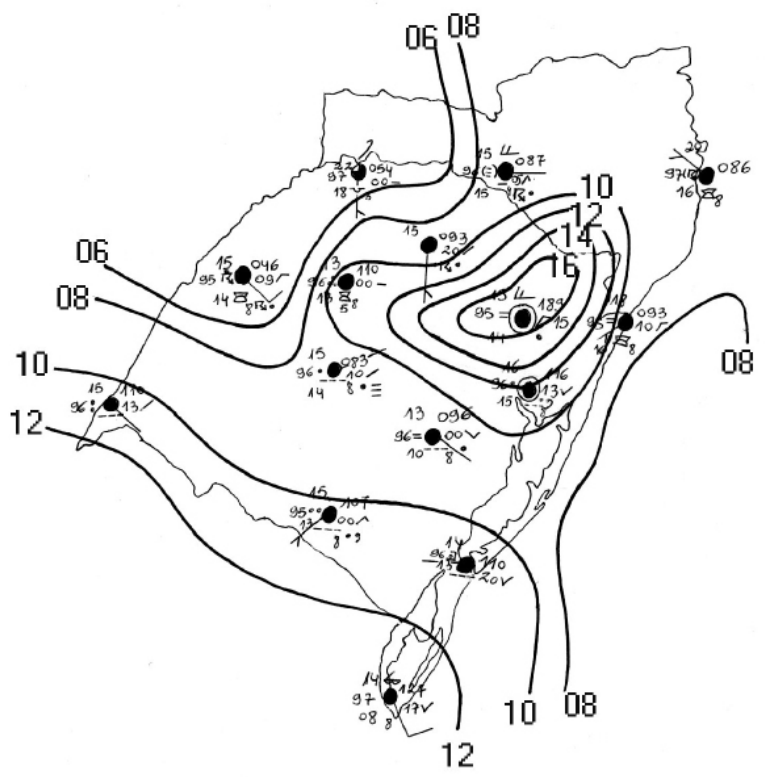

Figura 29 - Carta de superfície para o dia 1o de outubro de 1999, às 1200 UTC. 
Observando-se os dados plotados na carta, verifica-se que as estações que se encontravam na região sob a influência da frente quente, identificada na imagem de satélite, apresentaram precipitação com trovoada e, portanto, com a presença de nuvens de desenvolvimento vertical. Em outras estações, foi registrada alguma precipitação associada com a presença de nuvens estratiformes. Algumas estações registraram a presença de nevoeiro neste horário.

Na carta das 1800 UTC do mesmo dia (não mostrada) já se observava um sistema de alta pressão entrando no estado do Rio Grande do Sul. Na região centro-oeste podia-se observar um pequeno cavado, e na estação que se encontrava sob influência direta deste cavado, foi registrada precipitação com trovoadas. A mesma situação ocorreu em outras estações do Rio Grande do Sul localizadas na parte norte do estado, neste horário.

\section{CONCLUSÕES}

O estudo do primeiro caso típico de frente quente mostrou que o sistema passou no litoral do Rio Grande do Sul, causando mudanças no tempo num período aproximado de 24 horas.

Foram registradas nuvens cumulonimbus e cumulus de grande desenvolvimento vertical em várias estações do estado. Em estações do litoral foi observada a presença de precipitação, assim como, em outras localizadas no interior do estado, durante o período em que a zona frontal esteve atuando sobre o estado. Em algumas estações houve o registro de trovoadas associadas à passagem da frente.

No setor quente do vórtice ao qual estava associada a frente foi observado nevoeiro em várias estações. Na maioria delas foi registrada a ocorrência de nuvens de desenvolvimento vertical.

No campo de pressão reduzida ao nível médio do mar, verificou-se que a frente localizava-se no bordo oeste do anticiclone, cujas isóbaras, nesta região, apresentavam curvatura ciclônica. Analisando-se o mesmo campo para o estado do Rio Grande do Sul, encontrou-se um cavado de mesoescala.

Também ocorreu nevoeiro em algumas estações durante o período de atuação da zona frontal quente sobre o Rio Grande do Sul.

No segundo caso estudado, foi verificado que os valores de convergência observados em baixos níveis ( $925 \mathrm{hPa}$ ), na frente quente, eram iguais aos valores encontrados na retaguarda de uma frente fria. Já em altos níveis $(250 \mathrm{hPa})$ a frente fria mostrou um valor maior de divergência em comparação à frente quente.

Nos níveis de 1000 e $500 \mathrm{hPa}$, os valores de vorticidade na região da frente quente eram iguais àqueles encontrados na retaguarda da frente fria, porém em altos níveis $(250 \mathrm{hPa})$, a vorticidade anticiclônica na frente quente era maior do que na frente fria.
O segundo caso de frente quente analisado, não típico pela grande extensão da frente quente, também apresentou precipitação associada com a presença de nuvens convectivas. Contudo, o período de sua atuação sobre o estado foi mais curto: a banda frontal quente estava bem definida na imagem das 1145 UTC do dia $1^{\circ}$ de outubro de 1999 e na imagem das 1800 UTC do mesmo dia, já não se podia mais identificar a frente quente. Pelo boletim sinótico das 1200 UTC, verificou-se que as maiores precipitações foram registradas nas estações localizadas na região da zona frontal quente.

No primeiro caso, no boletim sinótico das 1200 UTC o maior valor de precipitação foi registrado em Santa Vitória do Palmar, no litoral sul do estado do Rio Grande do Sul, tendo sido observadas nuvens cumulonimbus neste horário, quando localizava-se sobre o litoral a retaguarda da zona frontal quente.

No segundo caso, a frente estava localizada na região de colo entre a alta do Atlântico e a alta polar e entre a baixa continental (térmica) localizada na parte centro-oeste da América do Sul e um ciclone extratropical localizado no Atlântico.

Notou-se que no caso da frente observada no dia 30 de junho de 1998, após deixar o estado, ela ainda podia ser definida na imagem de satélite sobre o Oceano Atlântico, enquanto na frente ocorrida no dia $1^{\circ}$ de outubro de 1999 , o mesmo não ocorreu e sobre o Atlântico já não se definia mais uma frente; existia apenas uma massa de nebulosidade, sem forma definida. Outro aspecto observado é que, no primeiro caso estudado, o vórtice ciclônico definiu-se mais claramente do que no segundo caso, no qual a espiral ciclônica não podia ser identificada de maneira nítida nas imagens de satélite.

\section{AGRADECIMENTOS}

As autoras agradecem ao Conselho Nacional de Desenvolvimento Científico e Tecnológico (CNPq) pelo financiamento deste trabalho no Centro de Pesquisas e Previsões Meteorológicas da Universidade Federal de Pelotas.

\section{REFERÊNCIAS BIBLIOGRÁFICAS}

ABDoulaeV, S., StARostin, A., LENSKAiA, O., GOMES, R. G. Sistemas de Mesoescala de precipitações no Rio Grande do Sul. Parte 4. Condições de Escala Sinótica do Desenvolvimento dos SMP. In: CONGRESSO BRASILEIRO DE METEOROLOGIA, 9, 1996, Campos do Jordão. Anais ....Campos do Jordão, 1996, v.2 p. 895-897. ANDERSON, R. K. , ASHMAN, G. R., FARR, G. R., FERGUSON, E. W., ISAYEVA, G. N., OLIVER, V. J., PARMENTER, F. C., POPOVA, T. P., SKIDMORE, R. W., SMITH, A.H., VELTISHCHEV, N. F. The use of satellite 
pictures in weather analysis and forecasting, Geneva, Organização Meteorológica Mundial, 1973.

ATKINSON, B. W., SMITH SON, P. A. Mesoscale precipitation areas in a warm frontal wave. Mon. Wea. Rev., p. 211-222, 1978.

BJERKNES, J., SOLBERG, H. Life cycle of cyclones and the polar front theory of atmospheric circulation. Geofys. Publ., v. III, n. 1, p.3-9, 1922.

BLUESTEIN, H. Synoptic-Dynamic Meteorology in Midlatitudes Vol. II -Observation and Theory of Weather Systems. New York: Oxford University Press, 1993. 594 p.

BROWNING, K. A. Conceptual models of precipitation systems. Weath. Forec., 1, p. 23-41, 1986.

BROWNIN, K. A., HARROLD, T. W. Air motion and precipitation growth in a wave depression. Quart. J. Roy. Meteorol. Soc. v.95, p.288-309, 1969.

DINIZ, F. A. Ciclone extratropical associado a uma frente fria (situação 28.05.84 a 30.05.84). In: CONGRESSO BRASILEIRO DE METEOROLOGIA, 3, 1984, Belo Horizonte. Anais, Belo Horizonte, 1984.v. 2, p. 246-268.

FEDOROVA, N. Meteorologia Sinótica. Pelotas: Editora da UFPel,, 1999. 259 p.

FEDOROVA, N., BAKST, L. Frontal Section Identification from Satellite Data. Part I. In: CONGRESSO BRASILEIRO DE METEOROLOGIA 9, 1996, Campos do Jordão, Anais, Campos do Jordão, 1996. p. 659-663.

FEDOROVA, N. BAKST, L. Identificação da advecção de ar quente através da análise de dados de satélites. Revista Brasileira de Geofísica, v. 17, n.1, p. 69-81, 1999.

FEDOROVA, N., KHAN, V. Análise de Complexos Convectivos de Mesoescala sobre o Sul do Brasil. Revista Brasileira de Meteorologia, v.14, n.1, p. 35-48, 1999.

FUNATSU, B. M. Estudo Sinótico-dinâmico de Ciclogênese usando Vorticidade Potencial. 2000. 147f. Dissertação (Mestrado em Meteorologia) - Instituto de Pesquisas Espaciais, São José dos Campos, 1986 (INPE-7264-TDI/706)

GAN, M. A., RAO, V. B. Surface Cyclogenesis over South America. Mon. Wea. Rev., 119, p. 1293-1302, 1991.

GREEN, J. S., LUDLAM, F. H., MCILVEEN, J. F. R. Isentropic relative flow-analysis and the parcel theory. Q. J. R. Meteorol. Soc., v. 92, p. 210-219, 1966.

HESS, S. Introduction to Theoretical Meteorology. New York: Holt, Rinehart and Winston, 1959. 361 p.

HOSKINS, B.J.; HECKLEY, W. A. Cold and warm fronts in baroclinic waves. Quart. J. R. Meteorol. Soc., v. 107, p. 79-90, 1981.
KOUSKY, V. E. Frontal influences on northeast Brazil. Mon. Wea. Rev., v. 107, p. 1140-53, 1979.

LIMA, J. S. Aspectos Climáticos da Região Metropolitana de Porto Alegre. Porto Alegre: Instituto de Proteção ao Vôo. Ministério da Aeronáutica, 1985. 54 p.

LOCATELLI, J. D., HOBBS, P. V. The mesoscale and microscale structure and organization of clouds and precipitation in midlatitude cyclones. XIII: Structure of a warm front. J. Atmos. Sci., v. 44, n. 16, p. 2290-2309, 1987.

MASS, C. F. Synoptical frontal analysis: time for a reassessment? Bull. Am. Meteorol. Soc., v. 72, n. 3, p. 348-363, 1991.

NEIMAN, P. J., RALPH, E. M., SHAPIRO, M. A. An observational study of fronts and front mergers over the continental United States. Mon. Wea. Rev., v. 126, p. 2521-2554, 1998.

OLIVEIRA, A. S. Interações entre sistemas frontais na América do Sul e a convecção na Amazônia. 1986. 134f. Dissertação (Mestrado em Meteorologia) - Instituto de Pesquisas Espaciais, São José dos Campos, 1986 (INPE4008-TDL/239).

PEDROTTI, C. B., FEDOROVA, N. Processos de formação de geada em Pelotas no ano de 1996. Rev. Bras. de Meteorol., v. 15, n.2, p. 1-19, 2000.

SEVERO, D. L. Estudo de casos de chuvas intensas no Estado de Santa Catarina. 1994. 97f. Dissertação (Mestrado em Meteorologia) - Instituto de Pesquisas Espaciais, São José dos Campos, 1994 (INPE-5682-TDI/568).

SIGNORINI, E., FEDOROVA, N., SILVA, R. S. Encontro entre ciclone térmico e um sistema frontal. Parte III: Análise da vorticidade relativa e divergência horizontal. In: CONGRESSO BRASILEIRO DE METEOROLOGIA, 10, 1998, Brasília. Anais... Campos do Jordão, 1998. CD-ROM.

TALJAARD, J. J. Synoptic Meteorology of the Southern Hemisphere. In: NEWTON, C. W. (Ed.). Meteorology of the Southern Hemisphere. Boston: American Meteorological Society, 1972. p. 139-211.

VASQUEZ, T. Weather Forecasting Handbook. Garland, Texas: Weather Graphics Technologies, 2000. 98 p.

ZWATZ-MEISE, V. Satellite-synoptic aspects of warm fronts. In: Meteosat Scientific User's Meeting, 8, 1990, Norrkoping. Proceedings ... Norrkoping, 1990. p. 151-160. 